6-30-2020

\title{
Building Assets for Humanitarian Settings
}

Women's Refugee Commission

Population Council

Follow this and additional works at: https://knowledgecommons.popcouncil.org/departments_sbsr-pgy

Part of the Family, Life Course, and Society Commons, Health Communication Commons, International Public Health Commons, and the Women's Health Commons How does access to this work benefit you? Let us know!

\section{Recommended Citation}

Women's Refugee Commission and Population Council. 2020. "Building Assets for Humanitarian Settings." New York: Population Council. 


\section{BUILDING ASSETS}

FOR HUMANITARIAN SETTINGS 


\section{POPULATION}

COUNCIL

Ideas. Evidence. Impact.

The Population Council confronts critical health and development issues-from stopping the spread of HIV to improving reproductive health and ensuring that young people lead full and productive lives. Through biomedical, social science, and public health research in 50 countries, we work with our partners to deliver solutions that lead to more effective policies, programs, and technologies that improve lives around the world. Established in 1952 and headquartered in New York, the Council is a nongovernmental, nonprofit organization governed by an international board of trustees.

\section{Population Council}

1 Dag Hammarskjold Plaza

New York, NY 10017

USA

Tel: +1 2123390500

Fax: +1 2127556052

popcouncil.org 


\section{BUILDING ASSETS FOR HUMANITARIAN SETTINGS}

Women's Refugee Commission (WRC) and the Population Council adapted the following draft Asset Exercise for use in humanitarian contexts, although they may be appropriate to many settings. Please refer to the original Building Assets Toolkit (https://www.popcouncil.org/uploads/pdfs/2015PGY_BuildingAssetsToolkitInstructionGuide.pdf) for full instructions on the activity and further resources (https://www.popcouncil.org/uploads/pdfs/2015PGY_ BuildingAssetsToolkitResourceManual.pdf).

\section{Facilitation Tips:}

- Select your deck: Each asset typically takes between 2-5 minutes to review; and not every "asset" is relevant to every context. So, take some time to select assets before beginning the activity. Plan to spend at least an hour on the exercise, and include between 35-50 asset cards. We have included guidance (below) on how to select specific assets during planning, but do not worry if you do not get through all of them during the exercise itself.

- Prepare your supplies: You will need tape and/or a space on the floor where you will have enough room to lay cards out in columns corresponding to each of the age cards. You will also need blank paper or index cards to use for new "asset" cards - so participants can volunteer their own ideas.

- Plan your session: The Asset Exercise is best with a group of 4-8 participants. If you have a large group, plan ahead: prepare multiple asset "decks," if possible, and select and brief a few participants to act as "facilitators" for this activity if you do not have enough outside facilitators.

- Introduce the activity: Explain all of the steps in the activity: reviewing assets, and assigning them to ages. Remember to emphasize that you are asking participants for the latest age when they believe girls should have each asset to ensure that they have it before they need to use it.

- Encourage participation: In settings where participants have limited literacy, the facilitator can read cards to the whole group, then invite participants to discuss where it should go. Otherwise, give each participant a small "deck" of cards and take turns reading the asset out loud and suggesting the age where they should go. The facilitator should encourage all of the group members to share their opinions and come to an agreement, but try not to push participants to select a specific age. If space permits, invite participants to take turns placing the assets on the wall, so everyone stays active and engaged throughout the exercise.

- Keep track of time: Make sure to leave enough time at the end of the exercise for participants to suggest additional assets; propose changes to where the assets are placed; and reflect on the results of the exercise as a group. 


\section{ASSET CARDS GUIDE}

The draft asset cards included in this "deck" are organized in two ways:

- Cards are grouped into three categories that will help you to prioritize the assets most appropriate to your context. These are marked by both their numerical order and borders:

\begin{tabular}{|c|c|c|c|}
\hline Numbers & Category & Definition & Notes \\
\hline $1-35$ & Core & $\begin{array}{l}\text { Relevant to all settings, } \\
\text { regardless of infrastructure, } \\
\text { policy, or social conditions. }\end{array}$ & $\begin{array}{l}\text { If you have limited time, use } \\
\text { this group only. You may note } \\
\text { that this includes topics such as } \\
\text { contraception and HIV that may } \\
\text { provoke discomfort: these should } \\
\text { still be included. }\end{array}$ \\
\hline
\end{tabular}

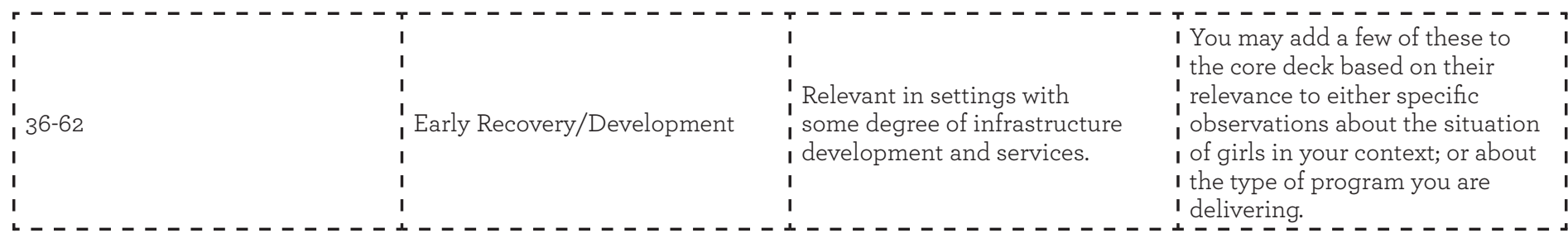

\begin{tabular}{|c|c|c|c|}
\hline $63-71$ & Context-Specfic & $\begin{array}{l}\text { Relevant in settings with specific } \\
\text { policy or social conditions. }\end{array}$ & $\begin{array}{l}\text { You may add a few of these to } \\
\text { the core deck based on both the } \\
\text { features of your context and their } \\
\text { salience for community members } \\
\text { and/or potential for programs or } \\
\text { services to address them. }\end{array}$ \\
\hline
\end{tabular}

- Cards are also marked by color codes, representing various domains:, which may further help you select assets or simply guide discussion:

\begin{tabular}{|c|c|c|}
\hline $5,36,37,40,45,50,51,64,65$ & Economic & $\begin{array}{l}\text { Relate to earning, saving, or } \\
\text { managing money }\end{array}$ \\
\hline $10,16,30$ & Education & $\begin{array}{l}\text { Contribute to concrete } \\
\text { skills-building and/or access to } \\
\text { school or alternative learning } \\
\text { environment }\end{array}$ \\
\hline $\begin{array}{l}1,3,4,6,7,8,11,15,25,26,27,32, \\
34,39,53,57,59,63,70\end{array}$ & Health & $\begin{array}{l}\text { Support healthy behaviors, } \\
\text { reduction in risks, and/or use of } \\
\text { health services }\end{array}$ \\
\hline $\begin{array}{l}17,18,24,33,35,38,44,49,55,56 \\
58,61,67,68,69,71\end{array}$ & Participation & $\begin{array}{l}\text { Address decision-making and } \\
\text { representation in public and } \\
\text { within household, exercise of } \\
\text { rights and access to entitlements }\end{array}$ \\
\hline $\begin{array}{l}2,9,12,13,14,20,21,22,23,29,41, \\
46,47,48,62,66\end{array}$ & Safety & $\begin{array}{l}\text { Promote physical security at } \\
\text { home, in institutional settings } \\
\text { and in public spaces }\end{array}$ \\
\hline $19,28,31,42,43,52,54,60$ & Social & $\begin{array}{l}\text { Relate to features of relationships } \\
\text { with self, peers, and adults }\end{array}$ \\
\hline
\end{tabular}




\section{ASSET LIST}

Number

\begin{tabular}{|c|c|c|}
\hline Number & Asset & $\begin{array}{l}\text { Domain (Economic, Education, } \\
\text { Health, Participation, Safety, Social) }\end{array}$ \\
\hline \multicolumn{3}{|c|}{ Core } \\
\hline 1 & Know location of emergency health services & Health \\
\hline 2 & Have a safe place to meet peers at least once a week & Safety \\
\hline 3 & $\begin{array}{l}\text { Know risks associated with persistent } \\
\text { diarrhea and how to manage }\end{array}$ & Health \\
\hline 4 & Know requirements for accessing SRH services & Health \\
\hline 5 & $\begin{array}{l}\text { Be able to assess risks associated with } \\
\text { different options for earning money }\end{array}$ & Economic \\
\hline 6 & Know specifics of menstruation and how to manage it & Health \\
\hline 7 & Know when, why, and how to wash hands & Health \\
\hline 8 & $\begin{array}{l}\text { Know signs of danger during pregnancy, labor, and where } \\
\text { to go for help }\end{array}$ & Health \\
\hline 9 & $\begin{array}{l}\text { Be able to describe her residence/home in relation to key } \\
\text { landmarks }\end{array}$ & Safety \\
\hline 10 & $\begin{array}{l}\text { Know how many years of primary and } \\
\text { secondary education to which she is entitled }\end{array}$ & Education \\
\hline 11 & Know how HIV is transmitted and how to prevent it & Health \\
\hline 12 & $\begin{array}{l}\text { Know where to turn for support if she or someone she } \\
\text { Knows has experienced } \\
\text { violence }\end{array}$ & Safety \\
\hline 13 & $\begin{array}{l}\text { Be aware that most violence against women and girls is } \\
\text { perpetrated by someone they Know }\end{array}$ & Safety \\
\hline 14 & $\begin{array}{l}\text { Know what abuse is and the difference } \\
\text { between a "good touch" and a "bad touch" }\end{array}$ & Safety \\
\hline 15 & Know basic nutritional needs of adolescent girls & Health \\
\hline 16 & Be able to read and write a sentence & Education \\
\hline 17 & Has all applicable identity documents & Participation \\
\hline 18 & $\begin{array}{l}\text { Know what programs government and NGOs provide for } \\
\text { girls their age }\end{array}$ & Participation \\
\hline 19 & $\begin{array}{l}\text { Be able to respectfully assert preferences for when to } \\
\text { marry and who to marry }\end{array}$ & Social \\
\hline 20 & Know the location of girl-only spaces & Safety \\
\hline 21 & $\begin{array}{l}\text { Be able to describe times of day and specific situations } \\
\text { when she feels unsafe }\end{array}$ & Safety \\
\hline 22 & $\begin{array}{l}\text { Be able to describe two strategies that may reduce her } \\
\text { exposure to common safety risks }\end{array}$ & Safety \\
\hline 23 & Know phone number to call when in need of help & Safety \\
\hline 24 & Know that she has the same rights as her brother & Participation \\
\hline 25 & $\begin{array}{l}\text { Be able to identify and Know when to test clean drinking } \\
\text { water sources }\end{array}$ & Health \\
\hline
\end{tabular}

Domain (Economic, Education, Health, Participation, Safety, Social) 


\begin{tabular}{|c|l|l|}
\hline 26 & $\begin{array}{l}\text { Know the routes to sources of clean water, and the } \\
\text { strategies for mitigating risks along the route to/from } \\
\text { water collection }\end{array}$ & Health \\
\hline 27 & Know where and how to get condoms and contraceptives & Health \\
\hline 28 & $\begin{array}{l}\text { Have a trustworthy adult who can provide accurate, } \\
\text { non-judgmental advice on contraception }\end{array}$ & Social \\
\hline 29 & $\begin{array}{l}\text { Know how to read a map, and where relevant, to identify } \\
\text { where she lives in relation to other features on the map }\end{array}$ & Safety \\
\hline 30 & $\begin{array}{l}\text { Be able to complete basic mathematical calculations (add, } \\
\text { subtract, multiple, divide) }\end{array}$ & Education \\
\hline 31 & $\begin{array}{l}\text { Feel like she can say “no" to her friends if they are } \\
\text { pressuring her to do something she doesn't think is right }\end{array}$ & Social \\
\hline 32 & $\begin{array}{l}\text { Know the symptoms that should prompt her or a family } \\
\text { member to seek medical attention (sustained fever, } \\
\text { persistent cough, diarrhea, blood in stool or phlegm, etc) }\end{array}$ & Health \\
\hline 33 & Has a birth certificate & Participation \\
\hline 34 & $\begin{array}{l}\text { Have access to supplies to manage menstruation every } \\
\text { month }\end{array}$ & Health \\
\hline 35 & $\begin{array}{l}\text { Know that according to international human rights } \\
\text { frameworks, marriage before a girl's 18th birthday is illegal } \\
\text { and that girls Have a right to determine when to marry and } \\
\text { who they marry }\end{array}$ & Participation \\
\hline
\end{tabular}

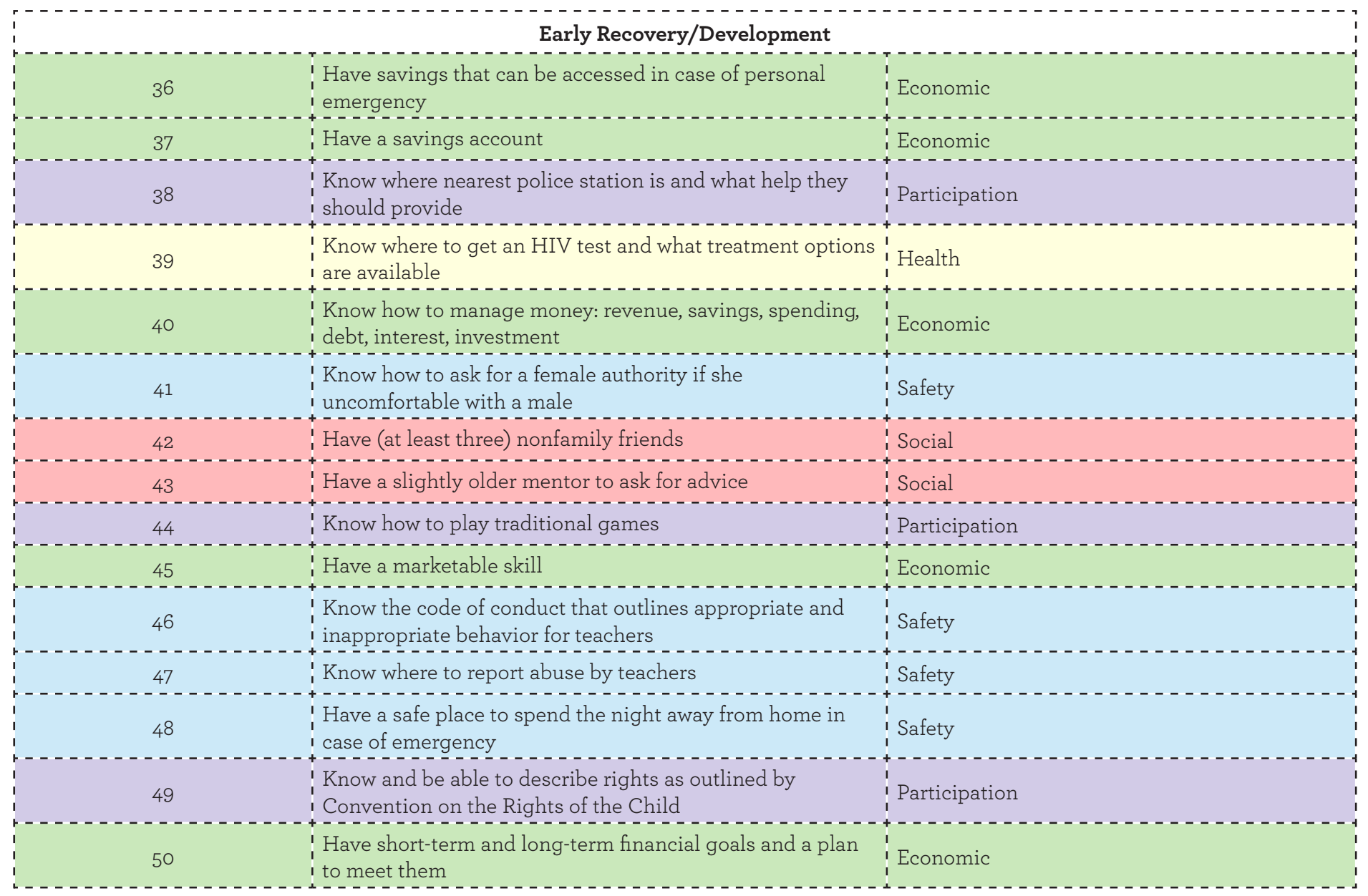




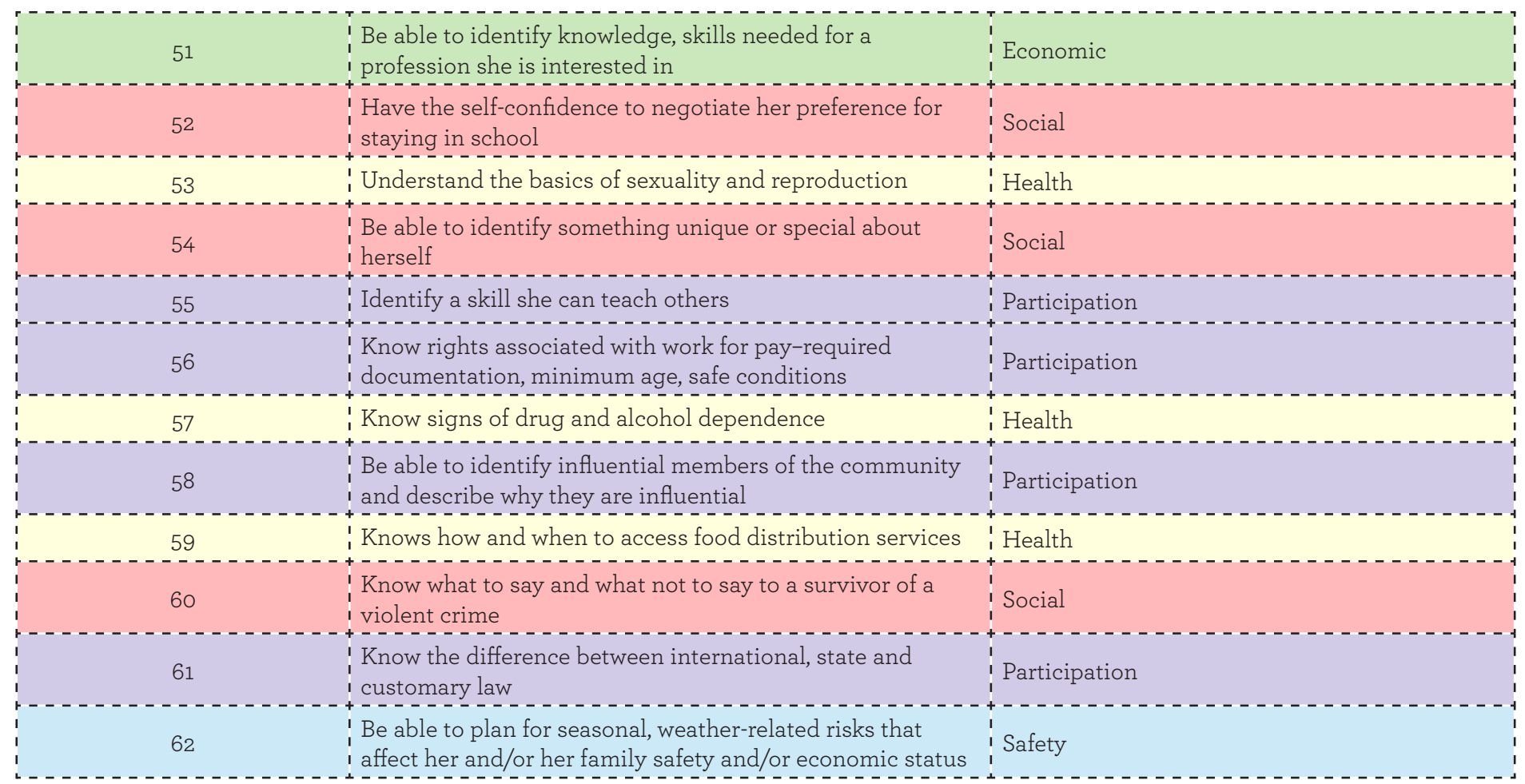

\section{Context-Specific}

63

64

65

66

67

68

69

70

71
Have accurate understanding of female genital cutting, its risks, and common myths/misinformation

Be able to borrow money under safe/reasonable lending terms

Know how to distinguish between a required expense and one that can be postponed

Have access and control over a portable light source

Know the legal voting age

Know where \& how to register to vote

Know where to vote

Know how to raise a few important foods

Know how to initiate conversations about traditional norms, including describing personal views and questioning them
Health

Economic

Economic

Safety

Participation

Participation

Participation

Health

Participation 


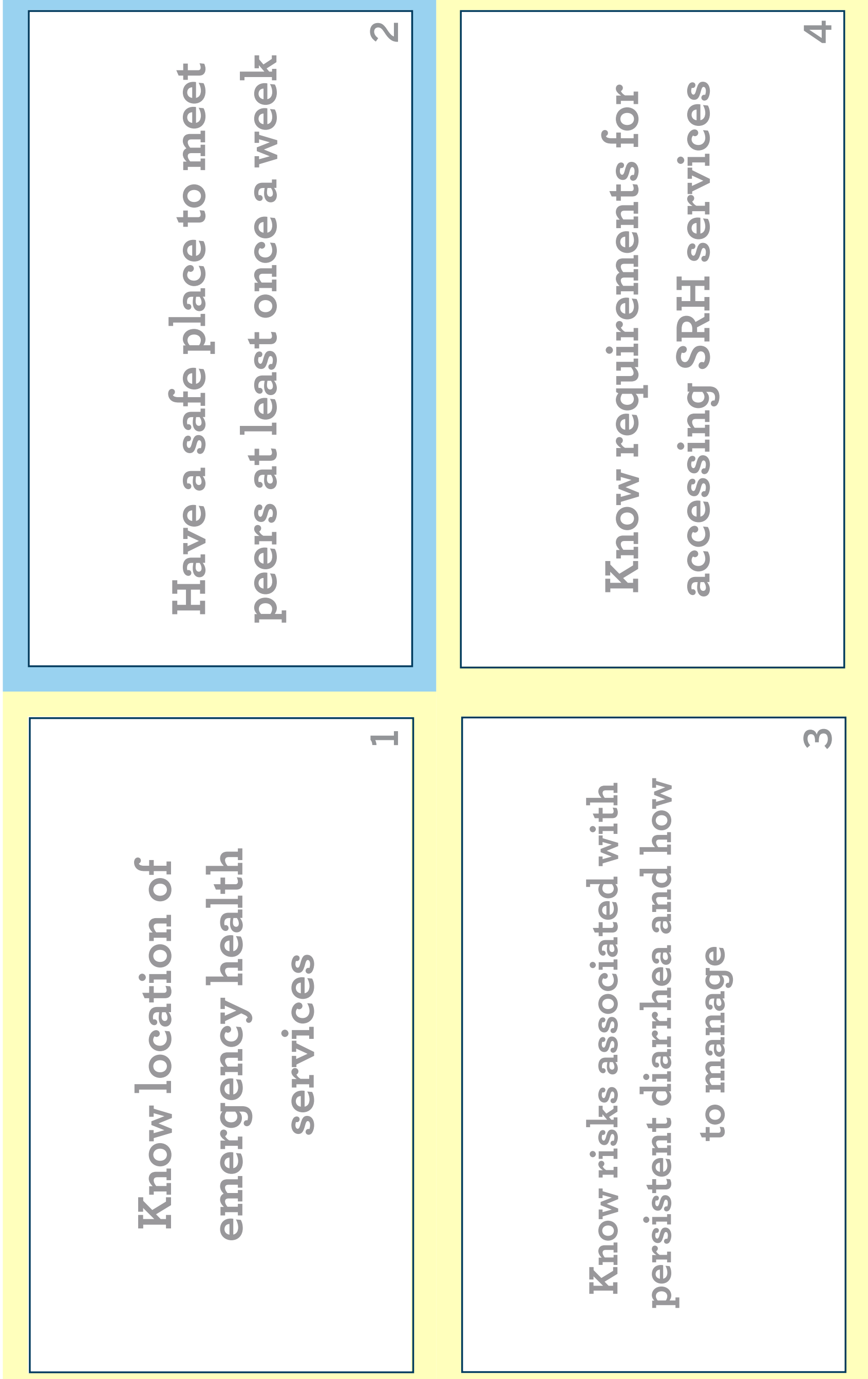

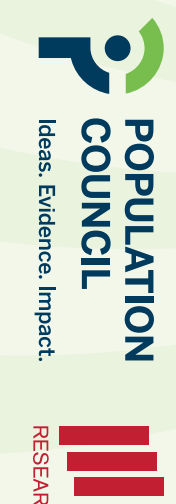
กิ1 $\Omega$ ס 꾼인 玄至飞 ○ $\mathrm{m}^{2}$

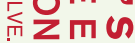
页
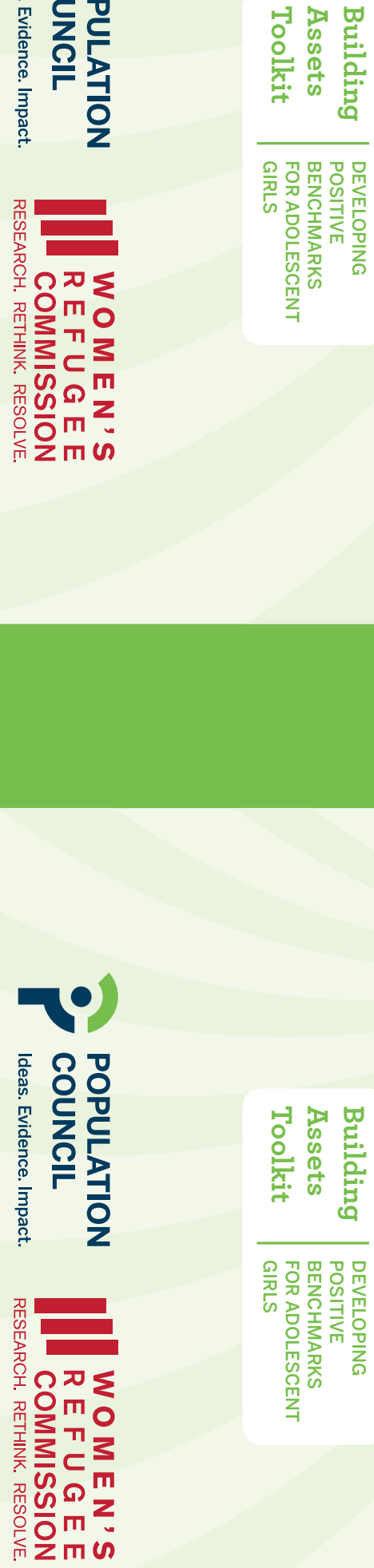
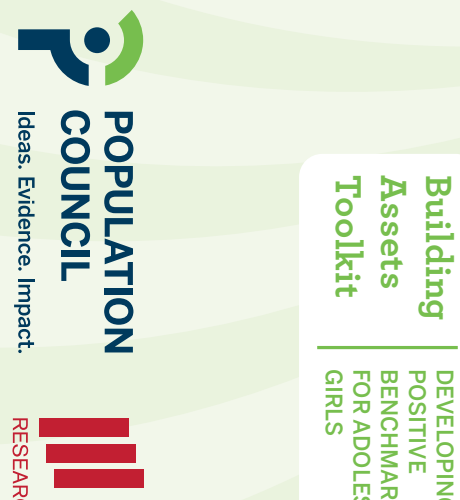

กิ工 $\cap$ ऽ

苗인

产 $\subset$

召心 $\boldsymbol{\omega}^{\mathrm{m}}$

을 而向心

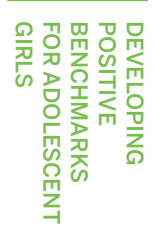

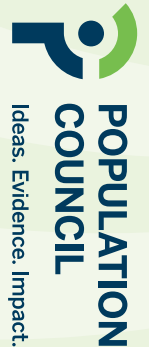

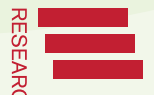

エฺ 备잉

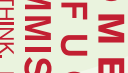
架 인

而两以 


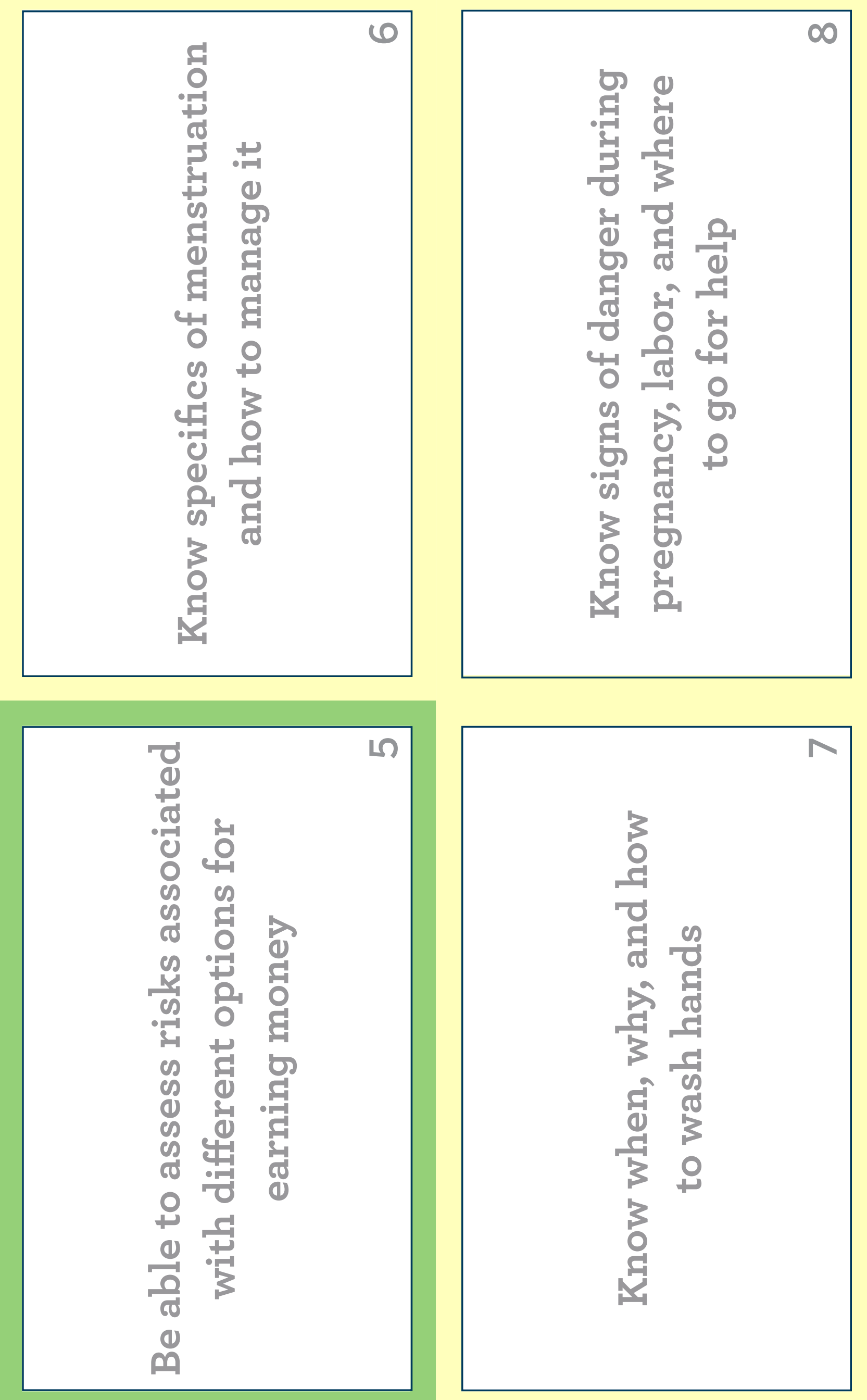



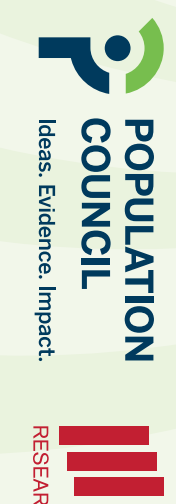
กิ1 $\Omega$ ס 꾼인 玄至飞 ○ $\mathrm{m}^{2}$

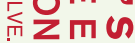
页
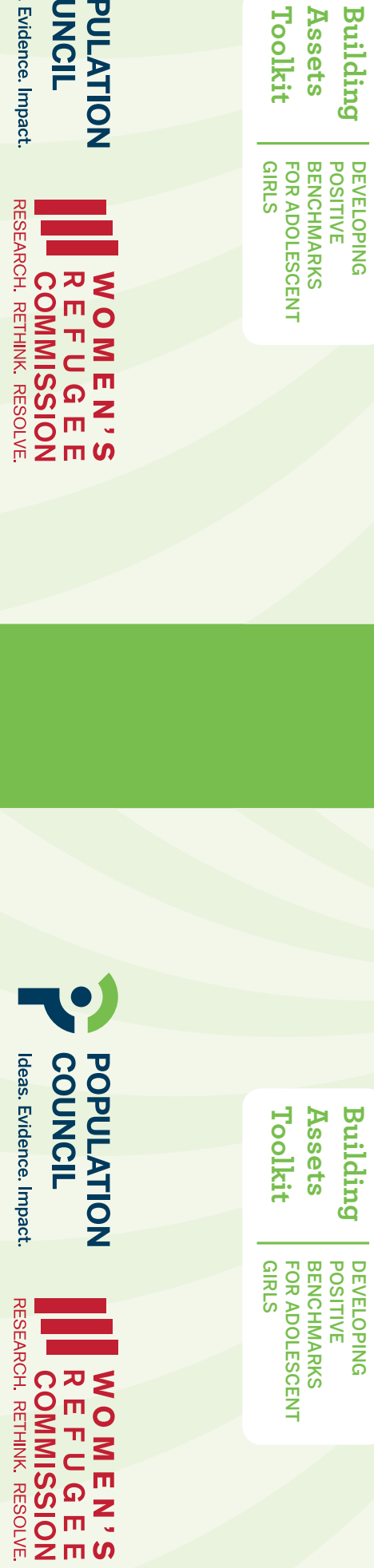
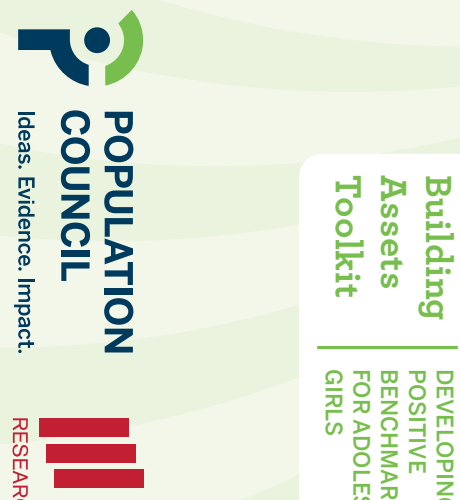

กิ工 $\cap$ ऽ

苗인

产 $\subset$

召心 $\boldsymbol{\omega}^{\mathrm{m}}$

을 而向心

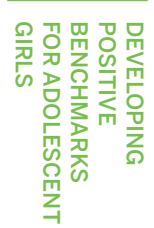

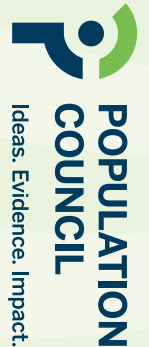

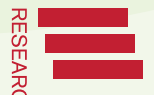

エฺ 备잉

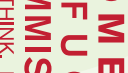
架 인

而两以 


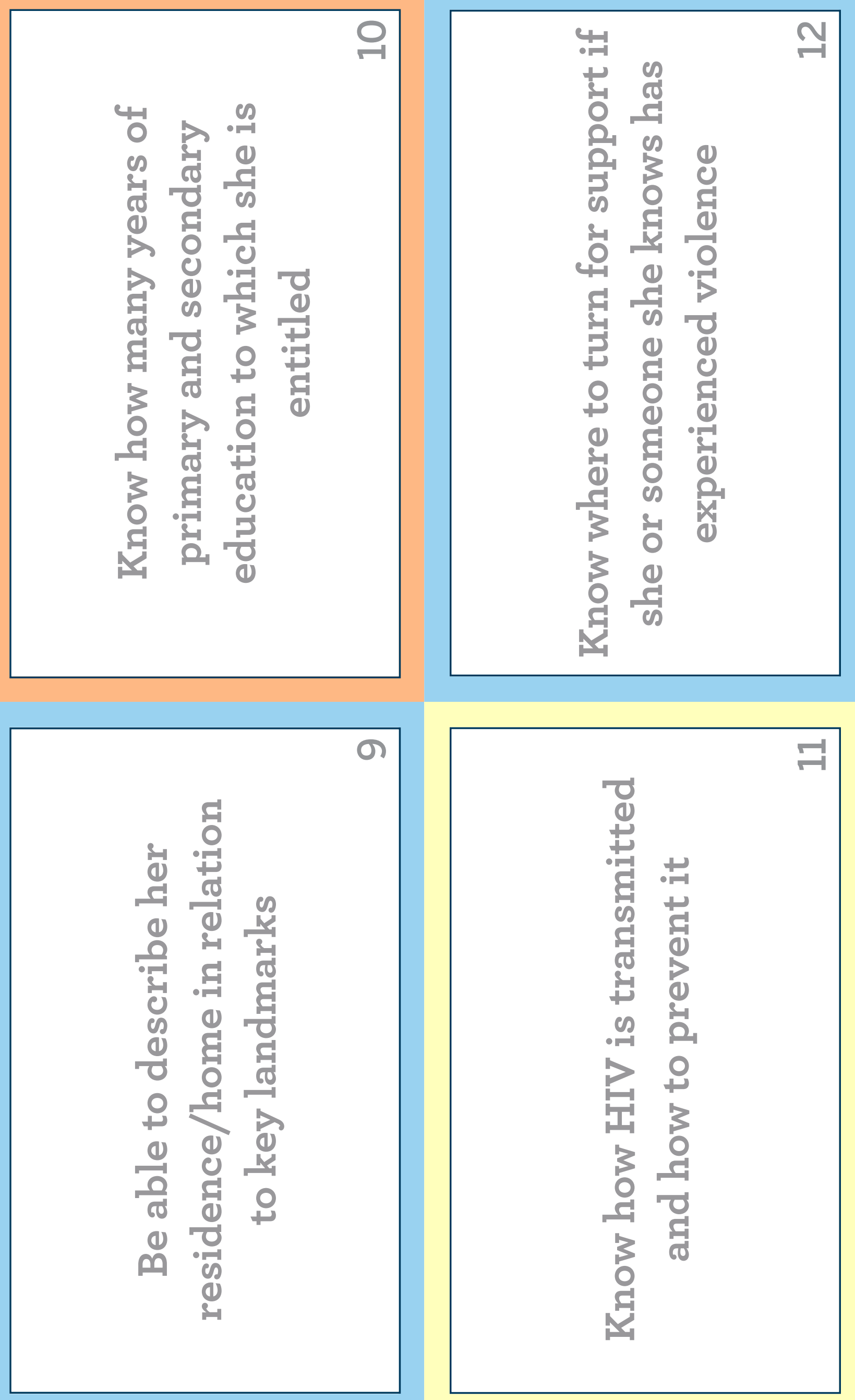



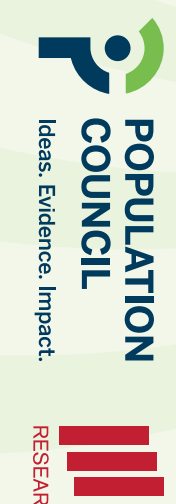
กิ1 $\Omega$ ס 꾼인 玄至飞 ○ $\mathrm{m}^{2}$

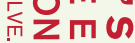
页
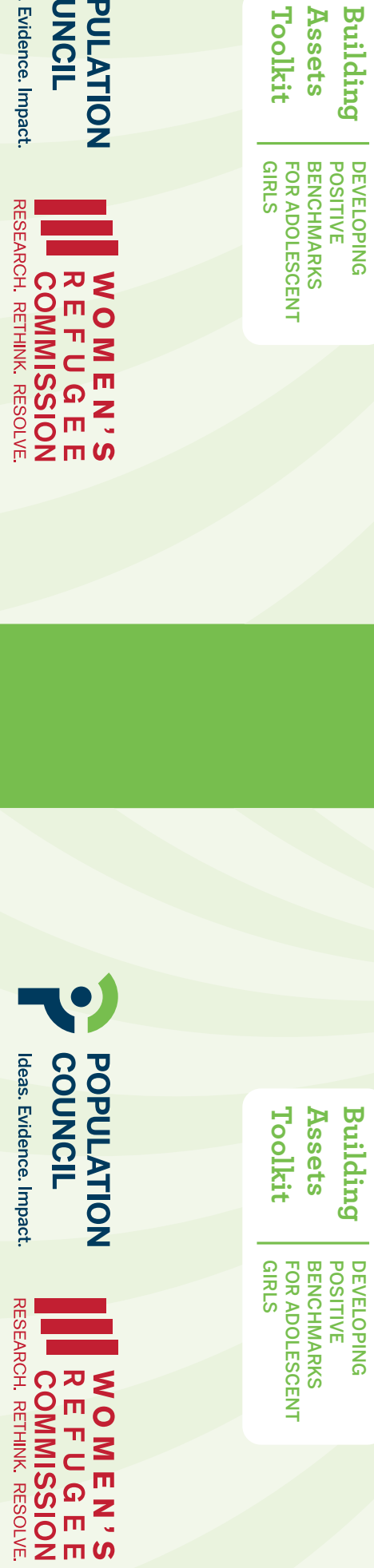
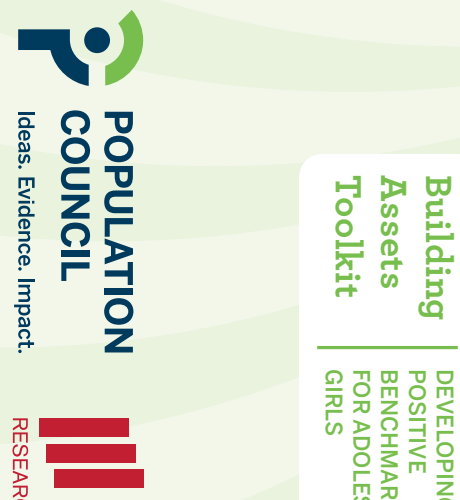

กิ工 $\cap$ ऽ

苗인

产 $\subset$

召心 $\boldsymbol{\omega}^{\mathrm{m}}$

을 而向心

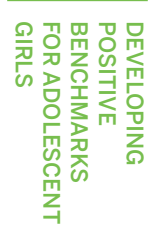

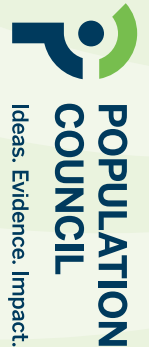

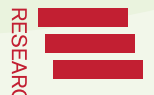

エฺ 备잉

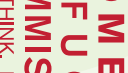
架 인

而两以 


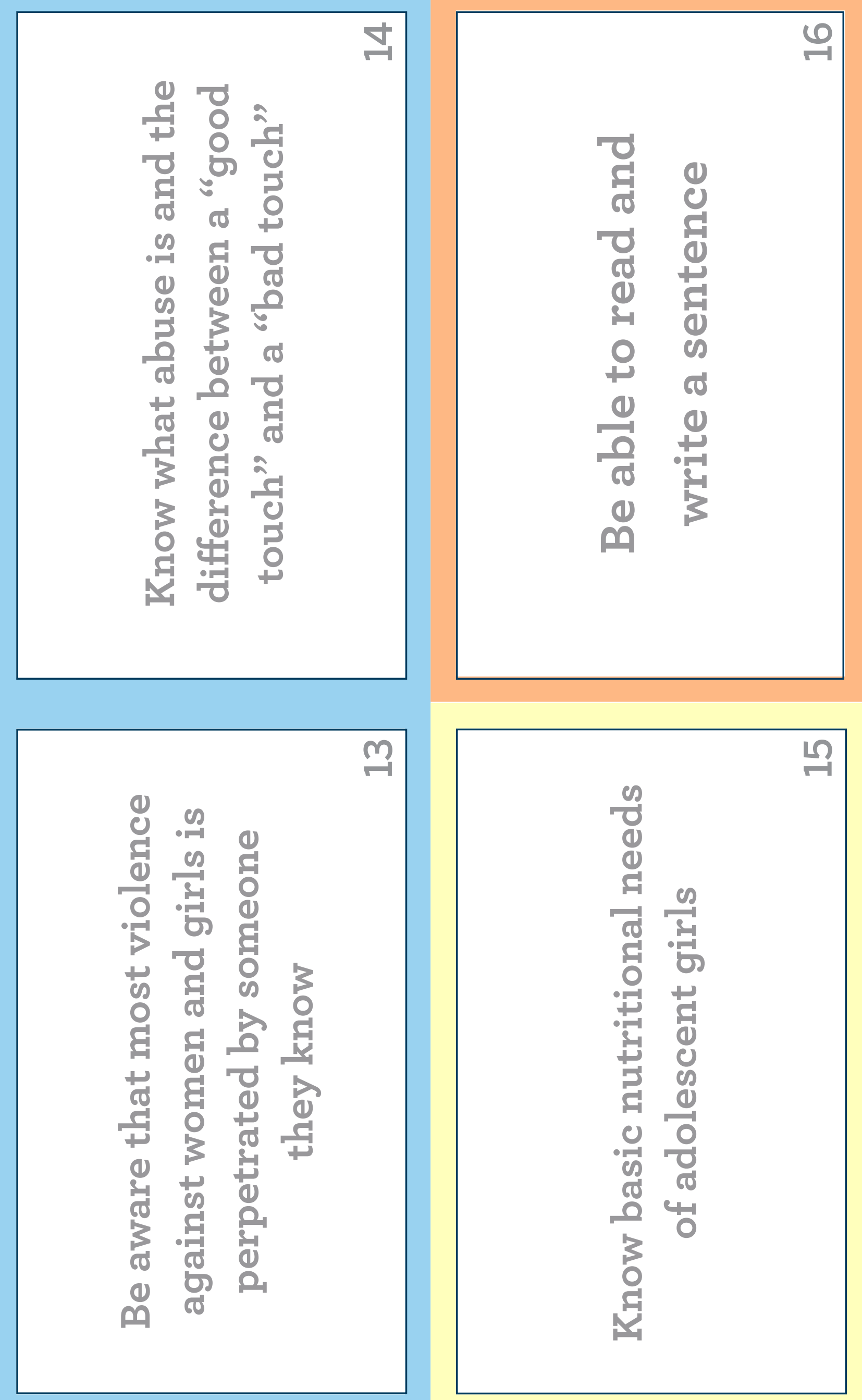



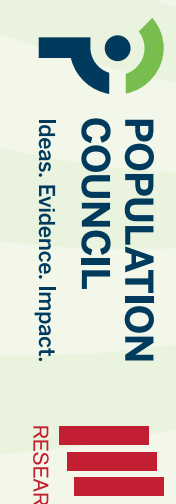
กิ1 $\Omega$ ס 꾼인 玄至飞 ○ $\mathrm{m}^{2}$

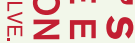
页
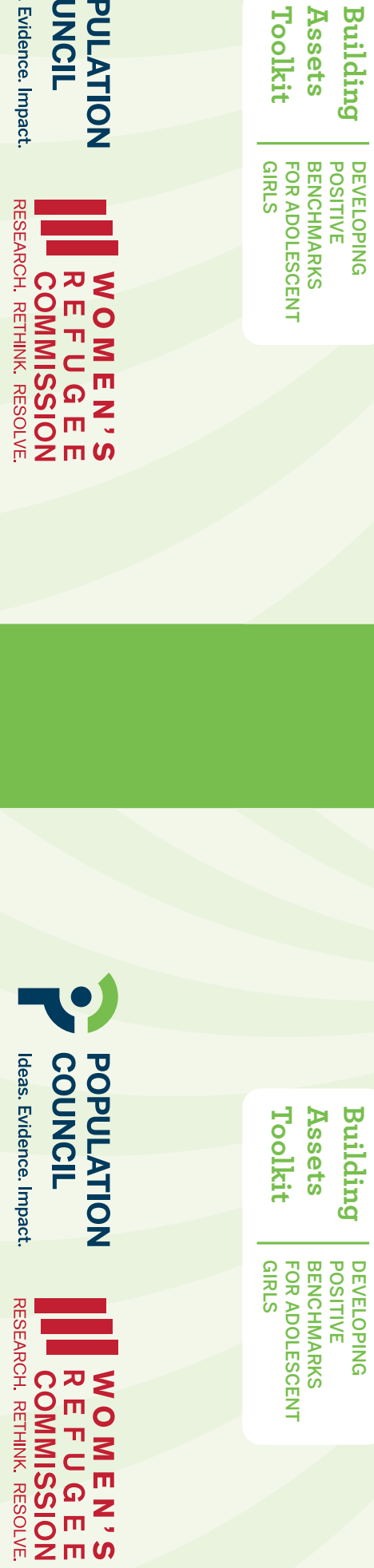
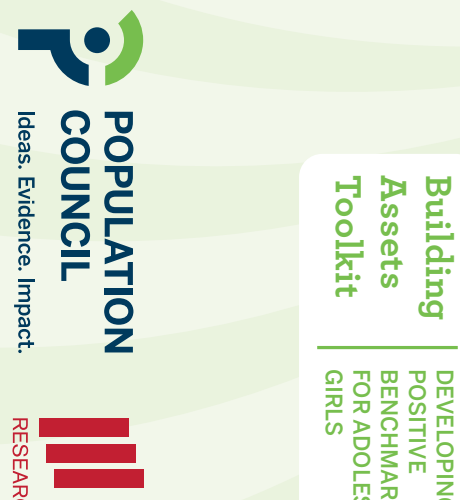

กิ工 $\cap$ ऽ

苗인

产 $\subset$

召心 $\boldsymbol{\omega}^{\mathrm{m}}$

을 而向心

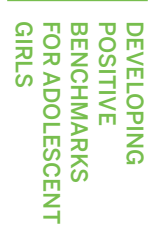

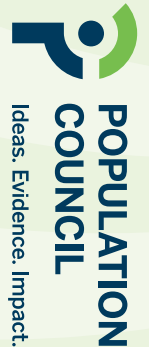

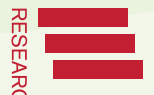

エฺ 备잉

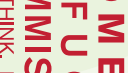
架 인

而两以 

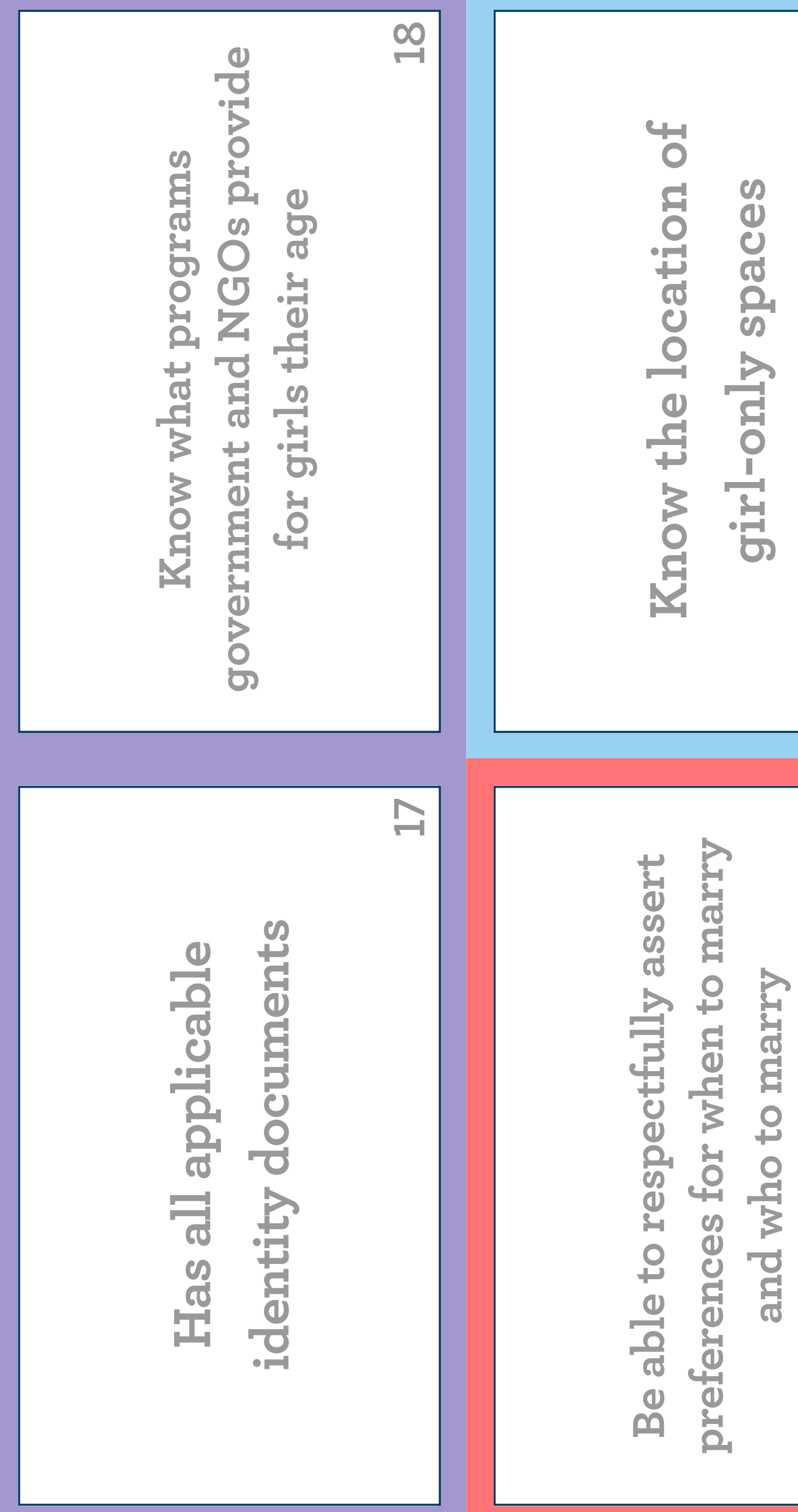

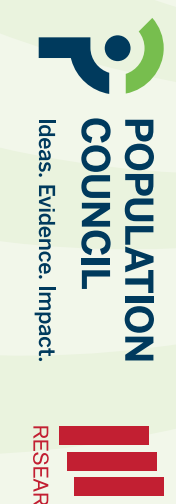
กิ1 $\Omega$ ס 꾼인 玄至飞 ○ $\mathrm{m}^{2}$

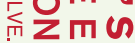
页
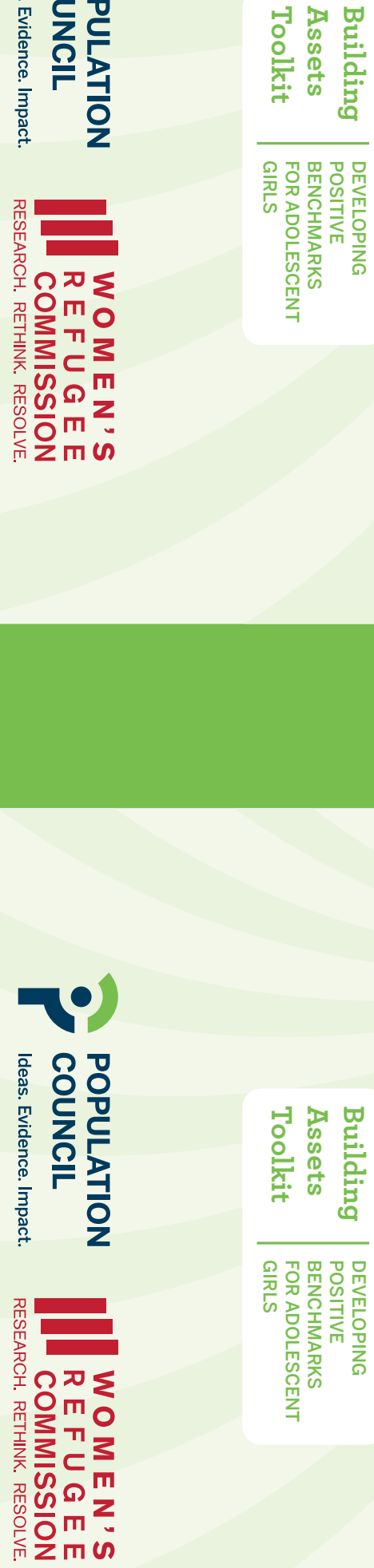
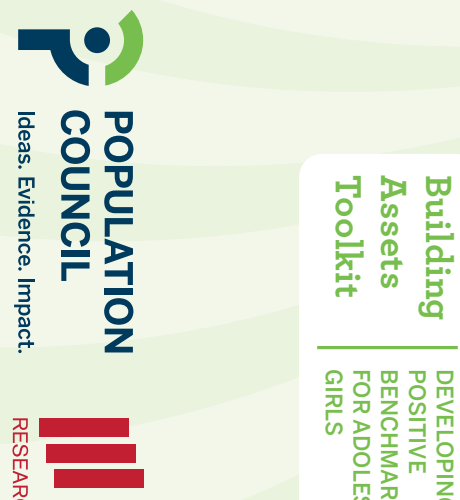

กิ工 $\cap$ ऽ

苗인

产 $\subset$

盄心

은 而向心

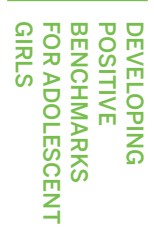

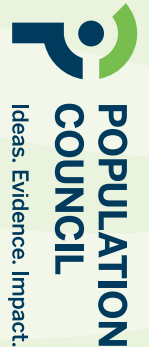

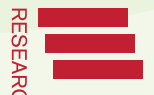

ำ 备잉

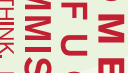
架 인

而两以 

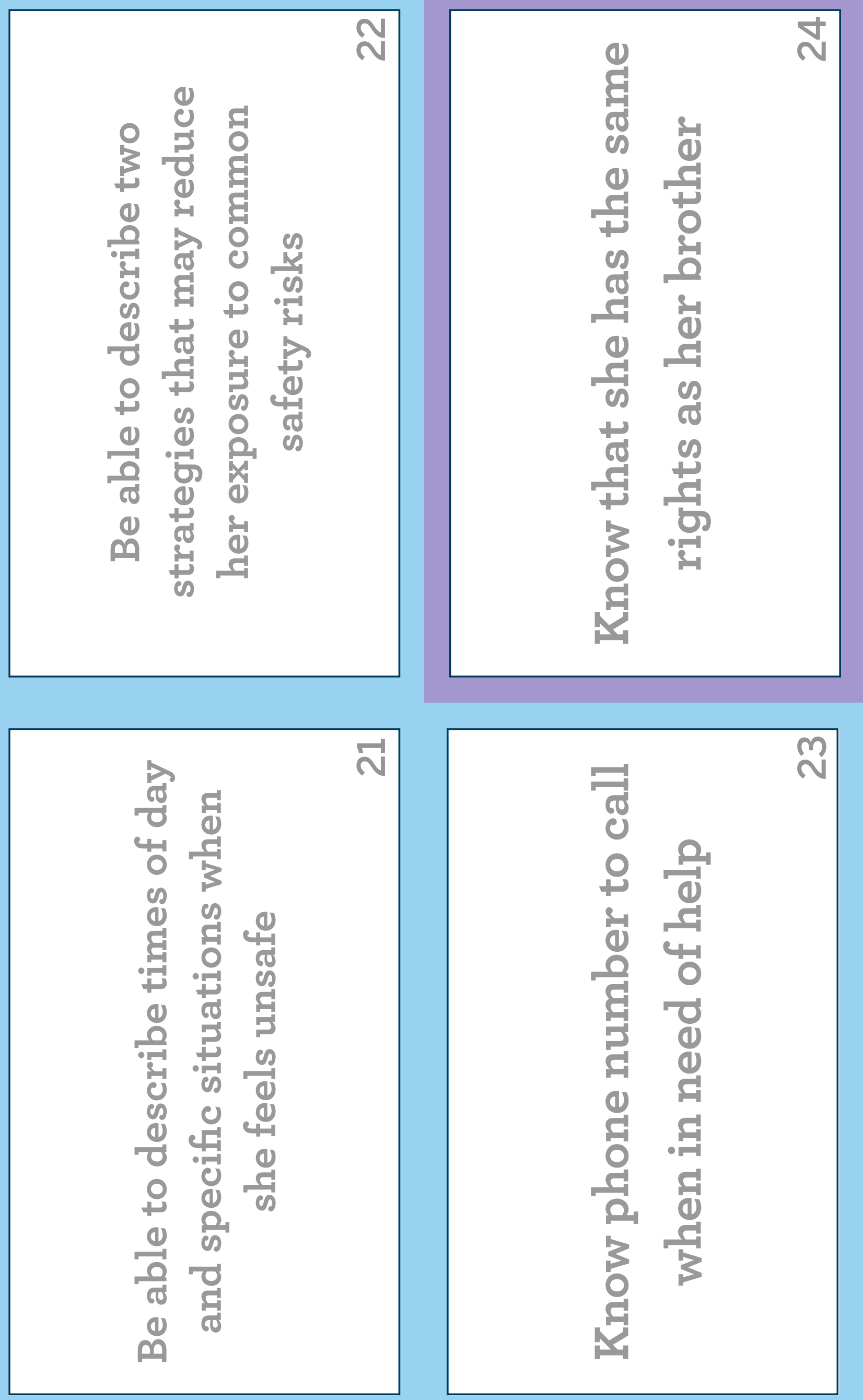

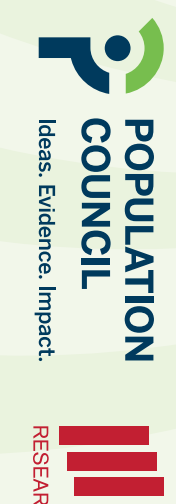
กิ1 $\Omega$ ס 꾼인 玄至飞 ○ $\mathrm{m}^{2}$

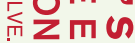
页
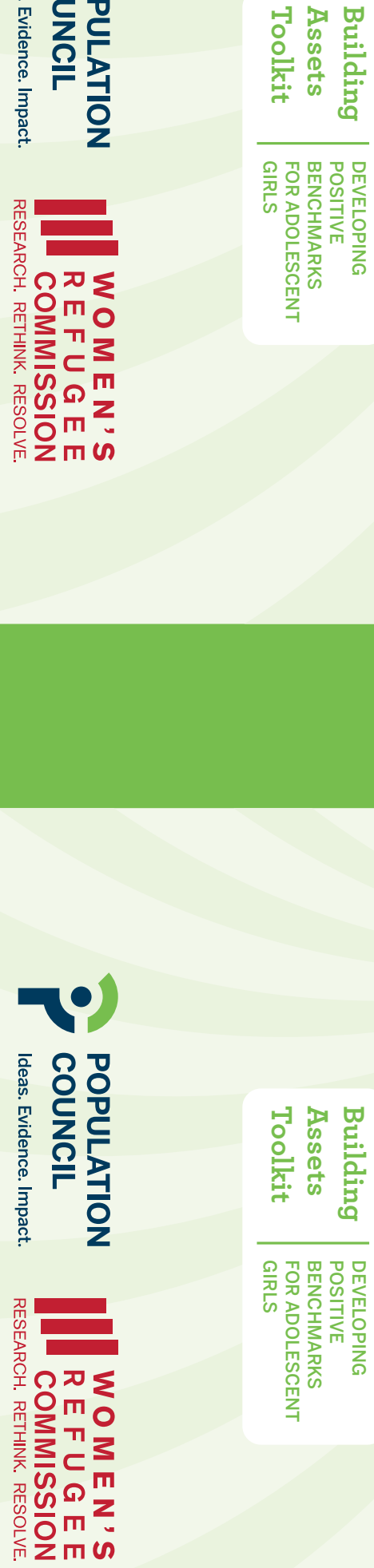
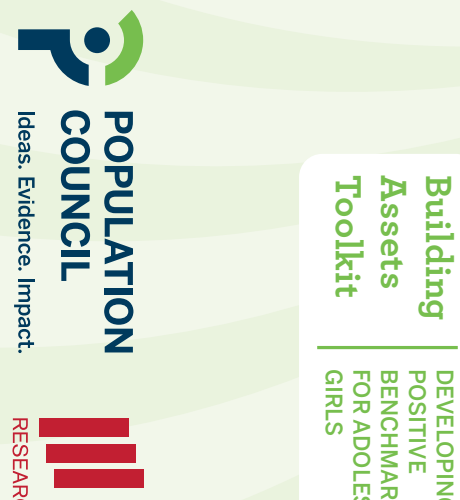

กิ工 $\cap$ ऽ

苗인

产 $\subset$

召心 $\boldsymbol{\omega}^{\mathrm{m}}$

을 而向心

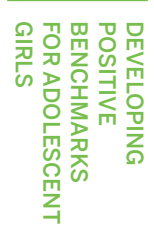

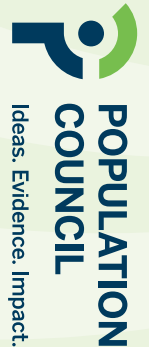

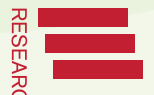

エฺ 备잉

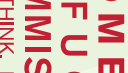
架 인

而两以 


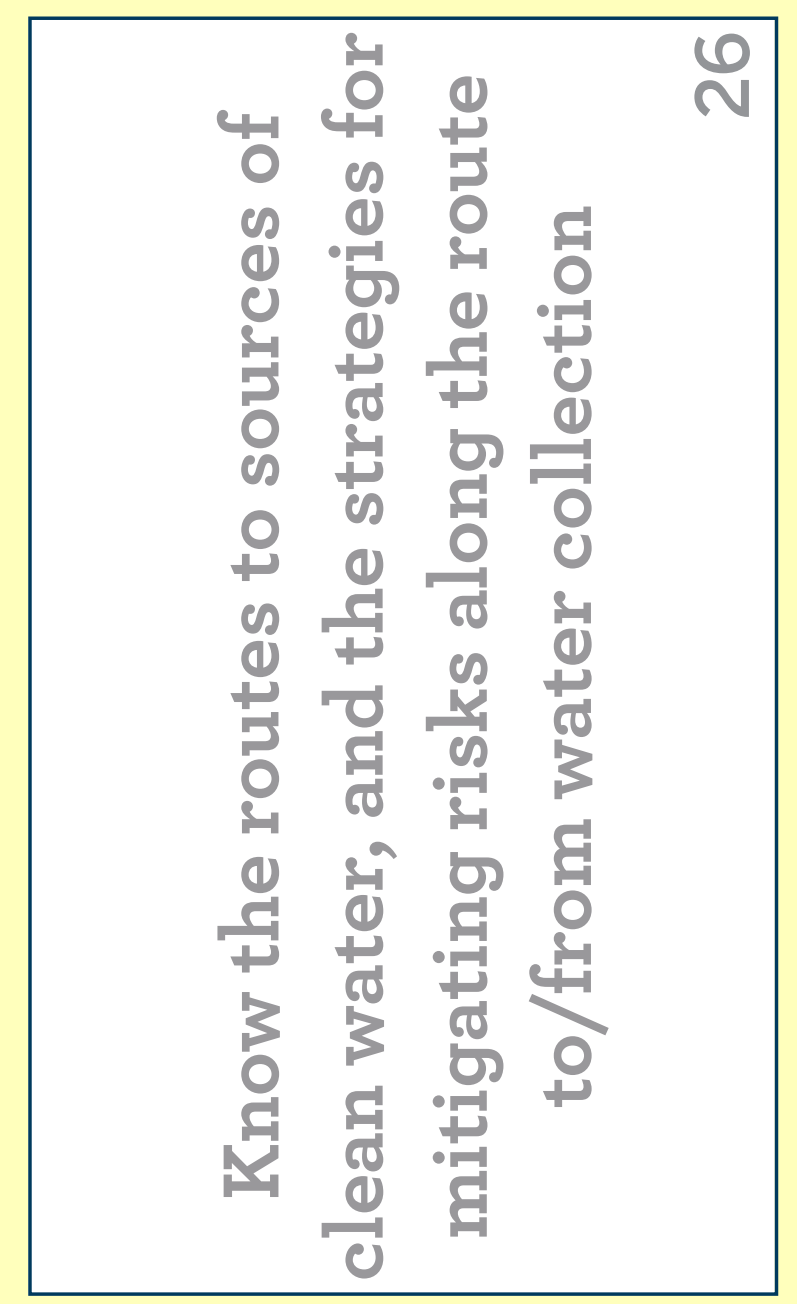

$\stackrel{\infty}{N}$

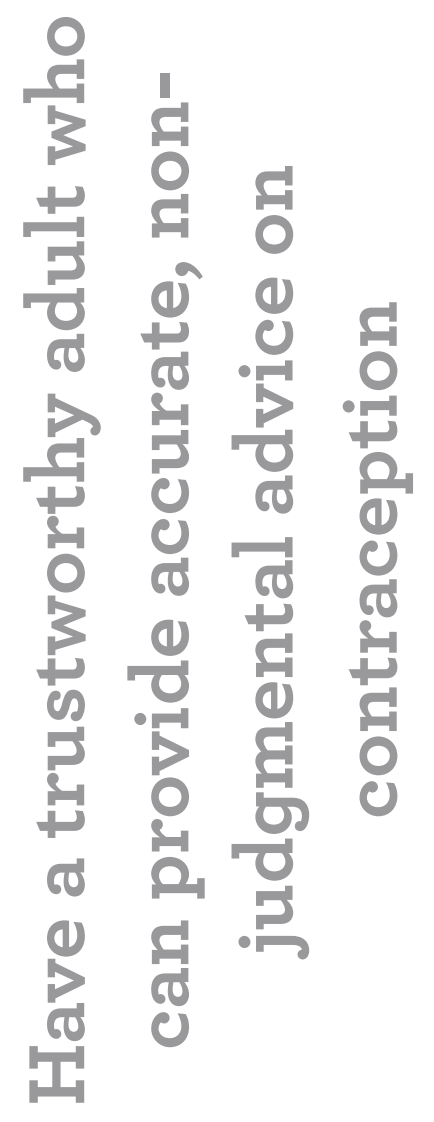

ก
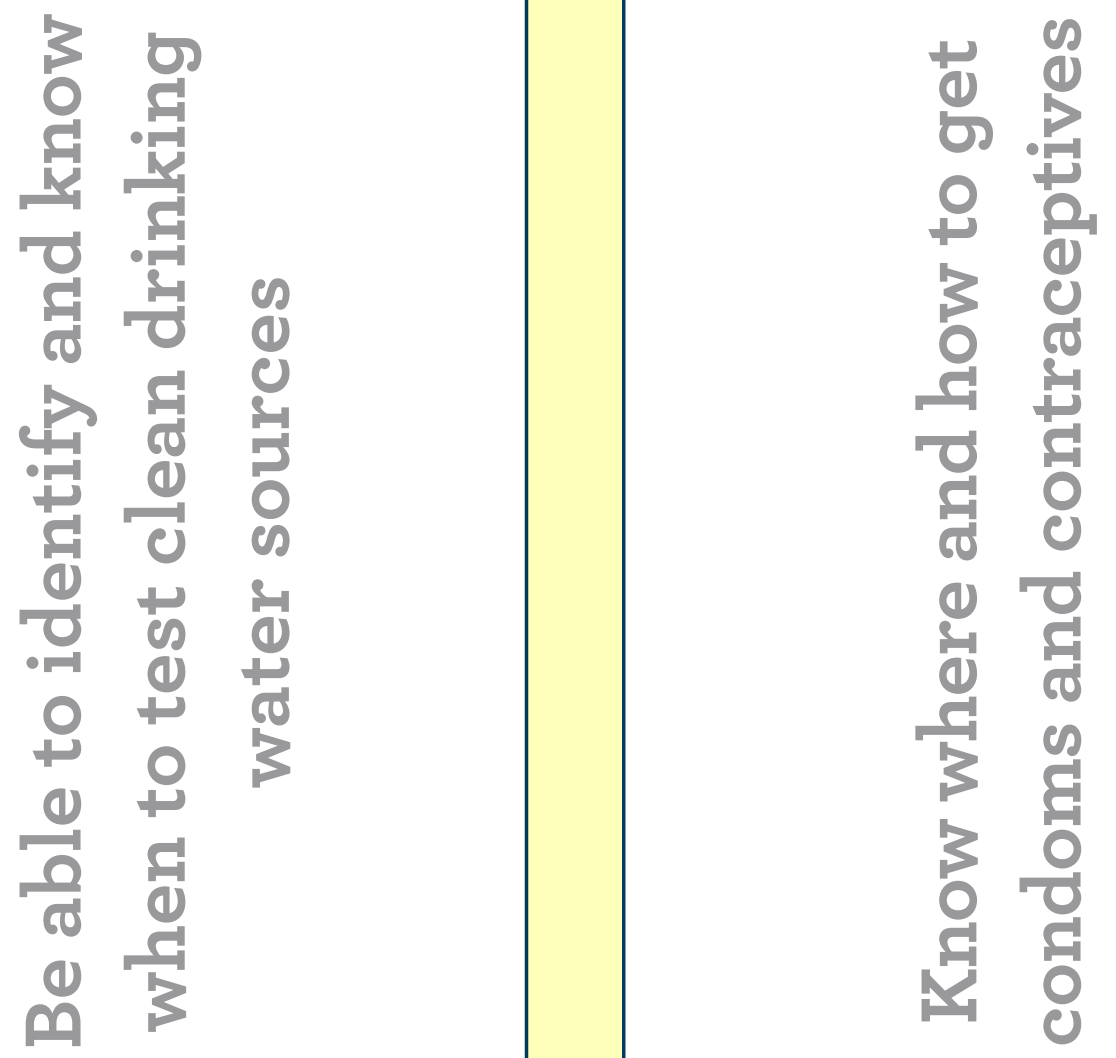

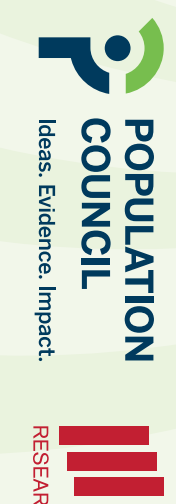
กิ1 $\Omega$ ס 꾼인 玄至飞 ○ $\mathrm{m}^{2}$

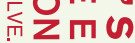
页
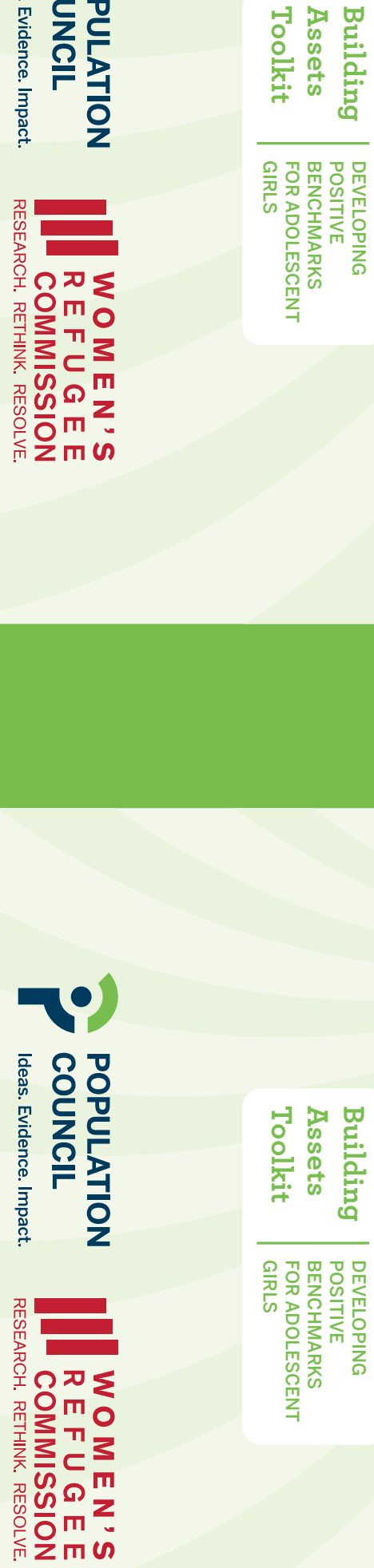
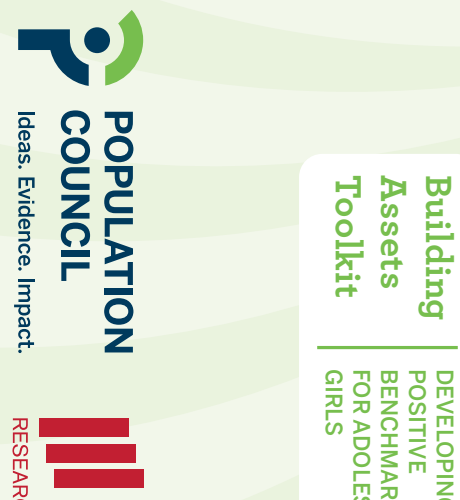

กิ工 $\cap$ ऽ

苗인

产 $\subset$

召心 $\boldsymbol{\omega}^{\mathrm{m}}$

을 而向心

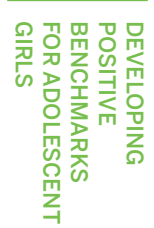

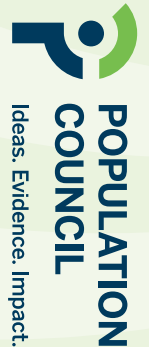

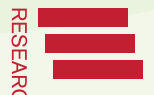

エฺ 备잉

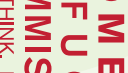
架 인

而两以 

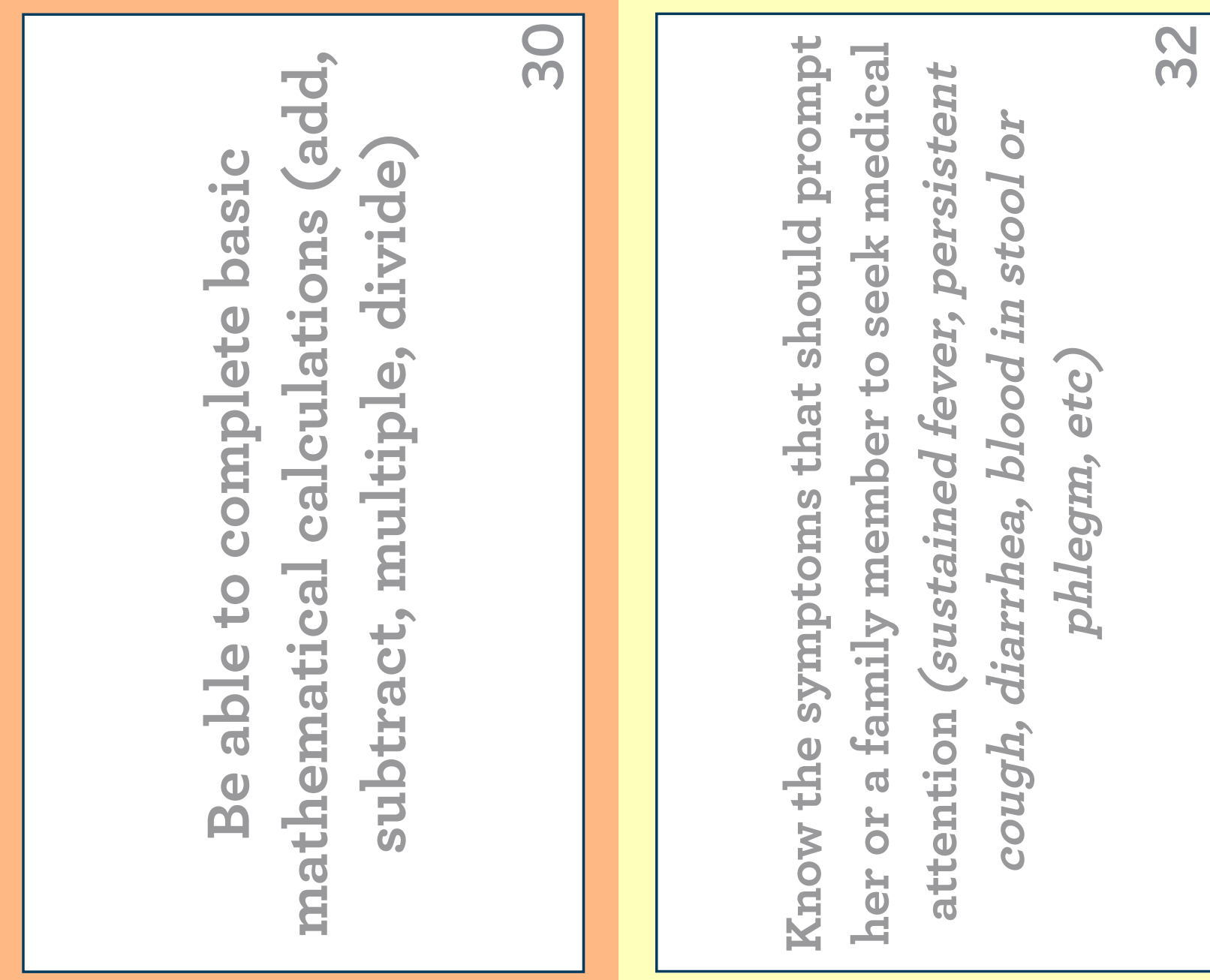

영 낭 영

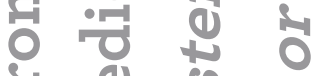

ค.

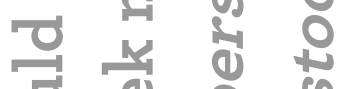

5 क क

年 ल क स

क 0 व 0

च

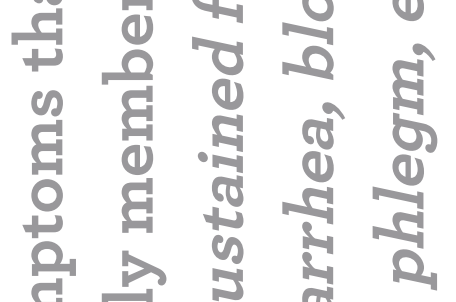

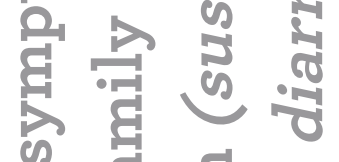

क त्व

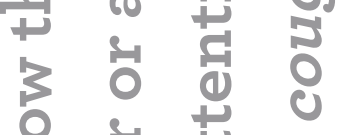

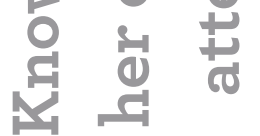

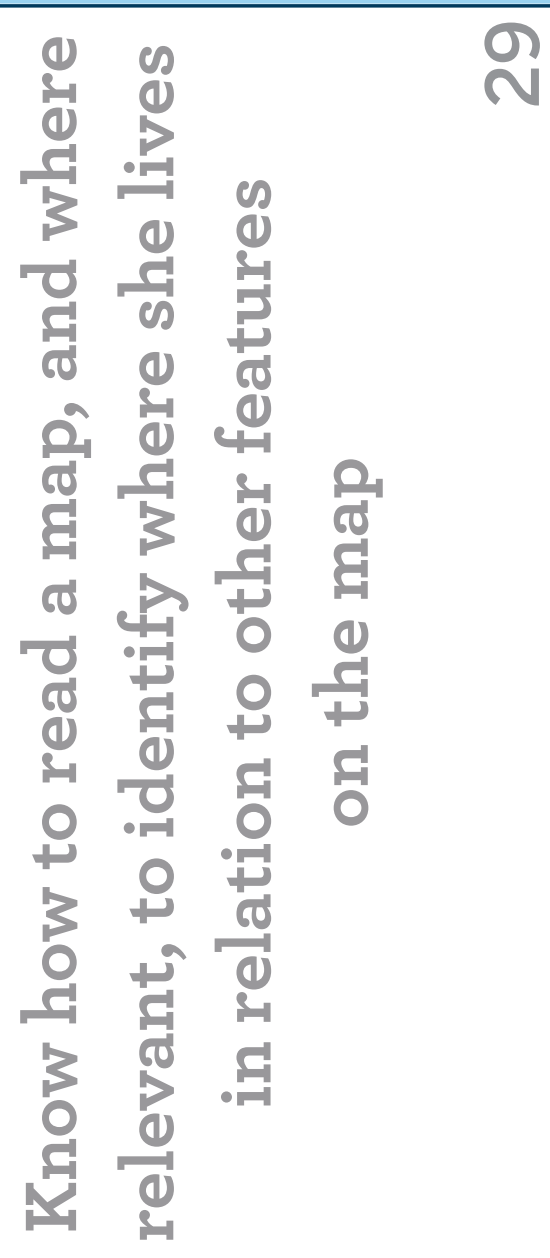



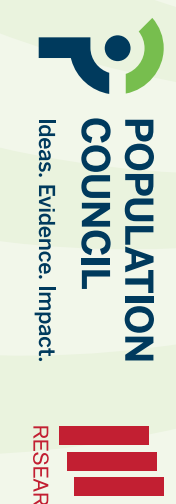
กิ1 $\Omega$ ס 꾼인 玄至飞 ○ $\mathrm{m}^{2}$

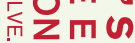
页
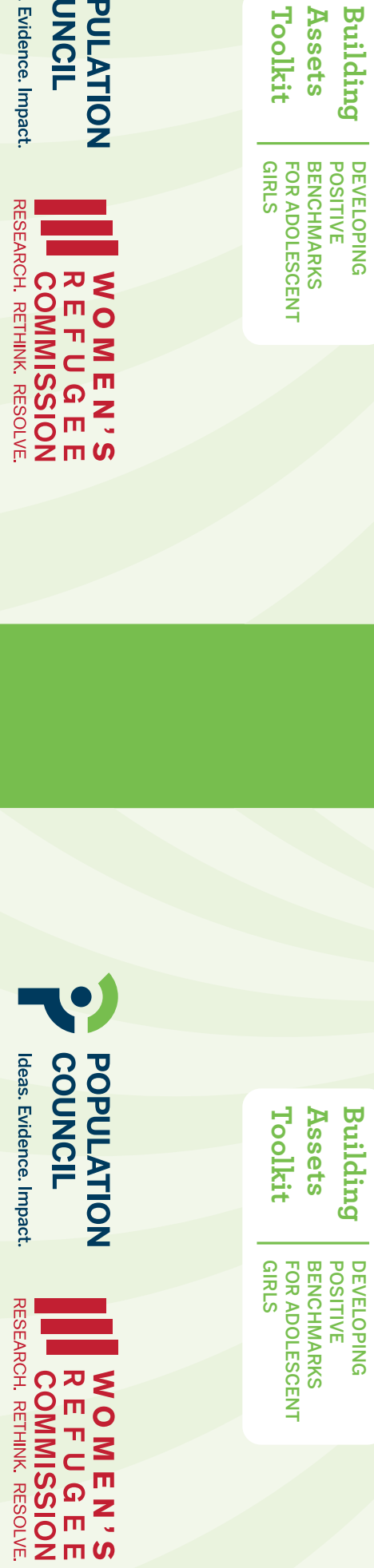
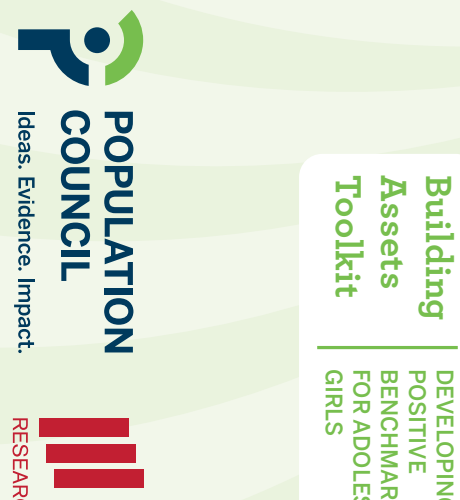

กิ工 $\cap$ ऽ

苗인

产 $\subset$

召心 $\boldsymbol{\omega}^{\mathrm{m}}$

을 而向心

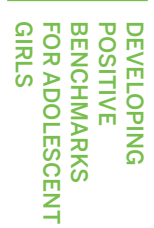

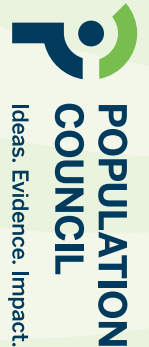

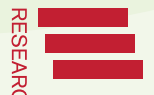

エฺ 备잉

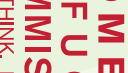
架 인

而两以 

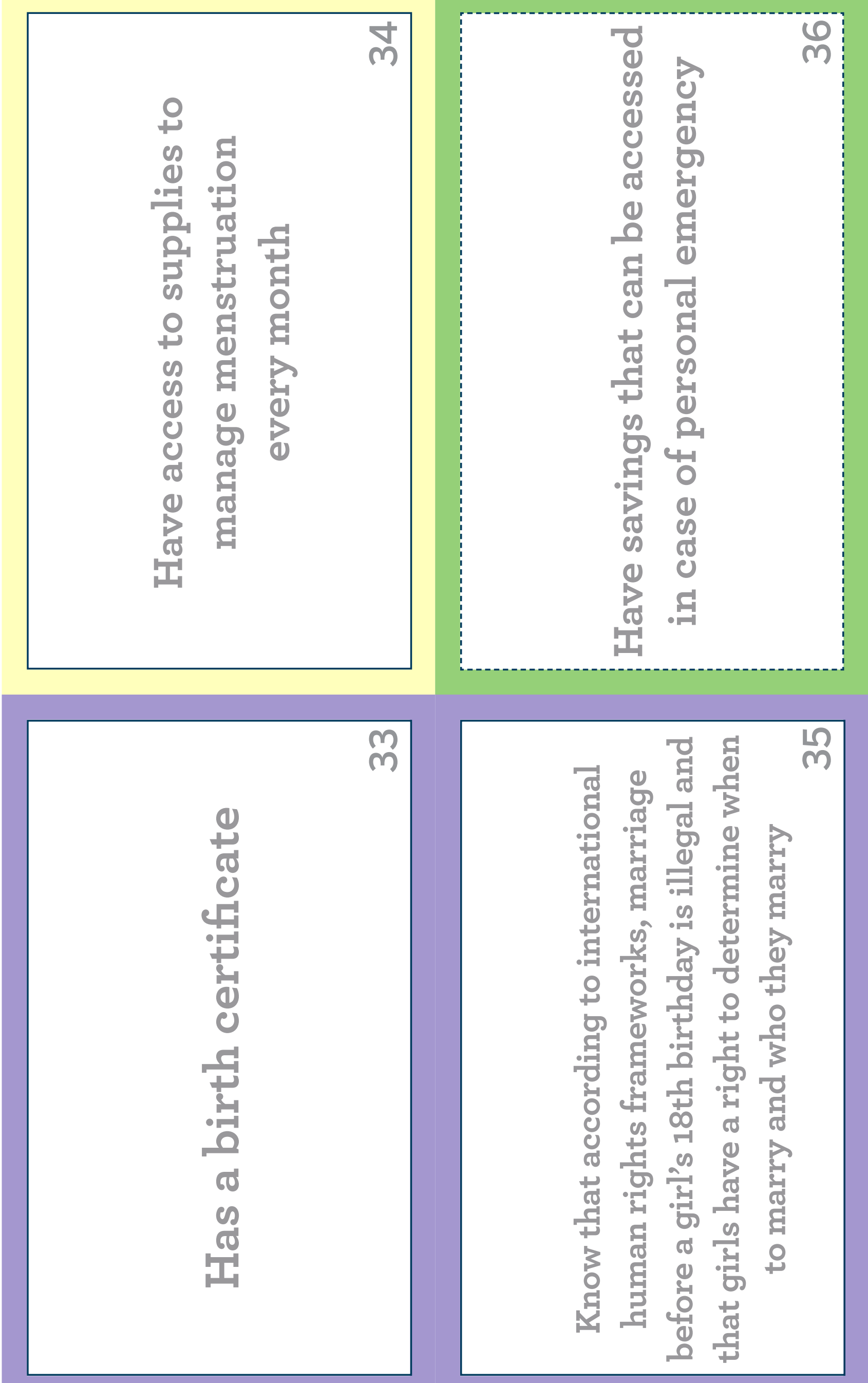

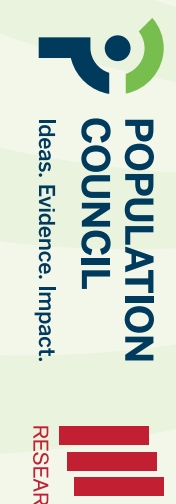
กิ1 $\Omega$ ס 꾼인 玄至飞 ○ $\mathrm{m}^{2}$

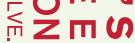
页
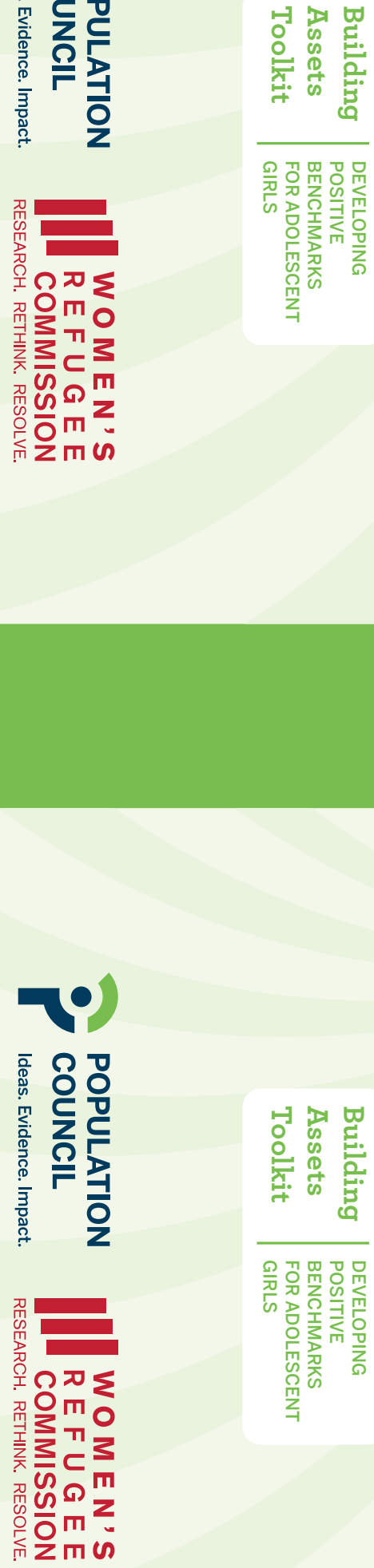
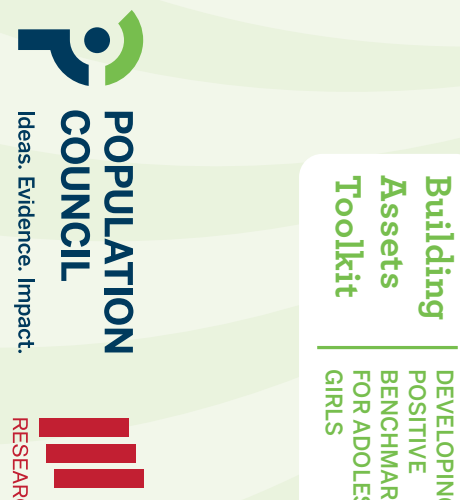

กิ工 $\cap$ ऽ

苗인

产 $\subset$

召心 $\boldsymbol{\omega}^{\mathrm{m}}$

을 而向心

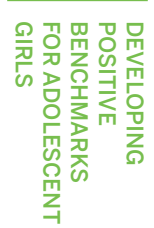

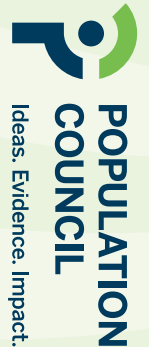

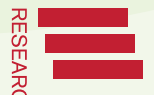

エฺ 备잉

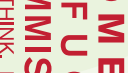
架 인

而两以 


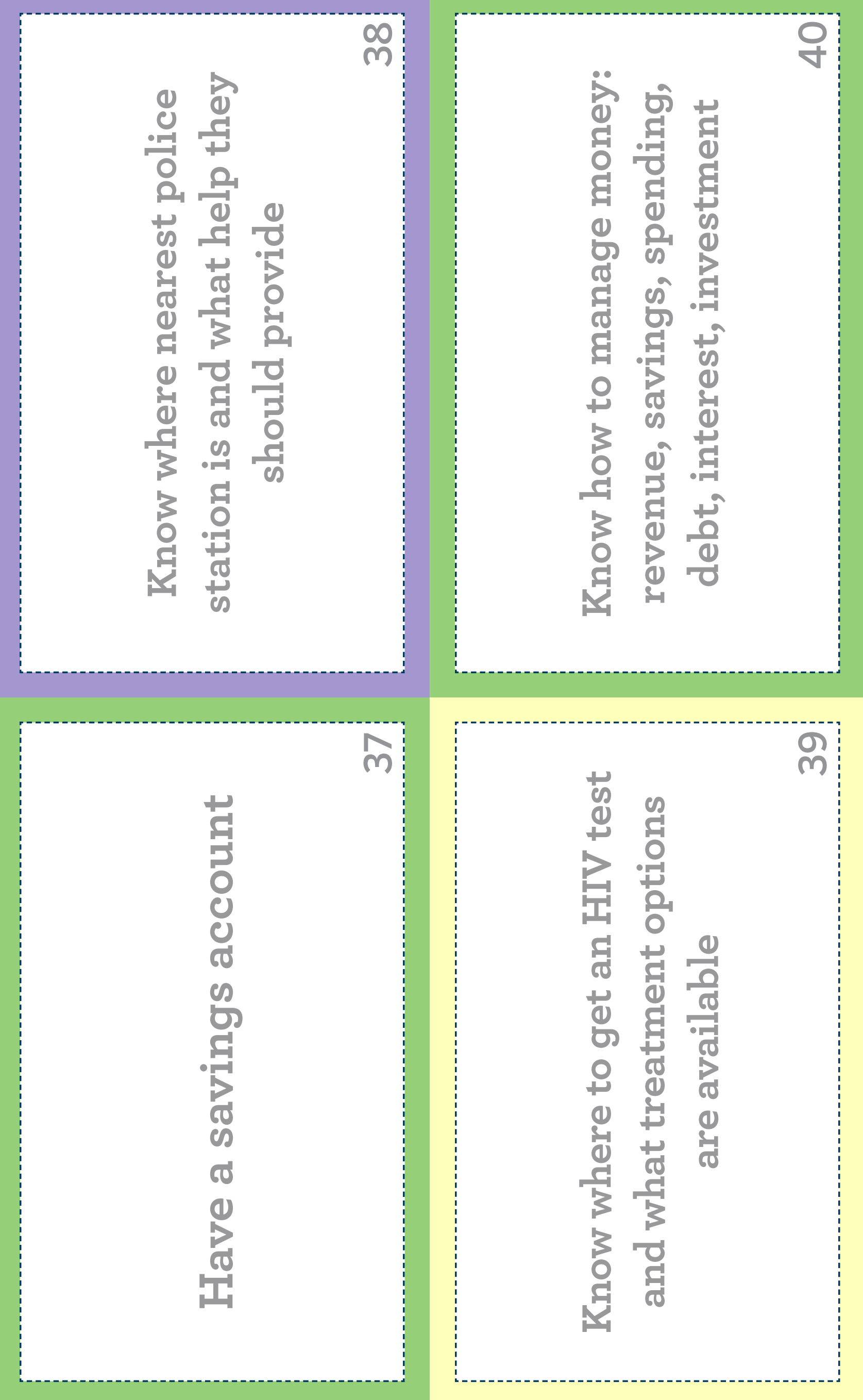



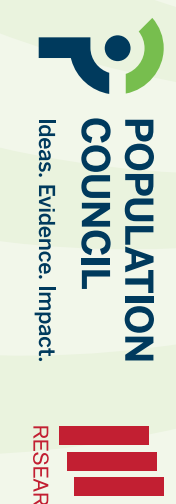
กิ1 $\Omega$ ס 꾼인 玄至飞 ○ $\mathrm{m}^{2}$

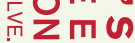
页
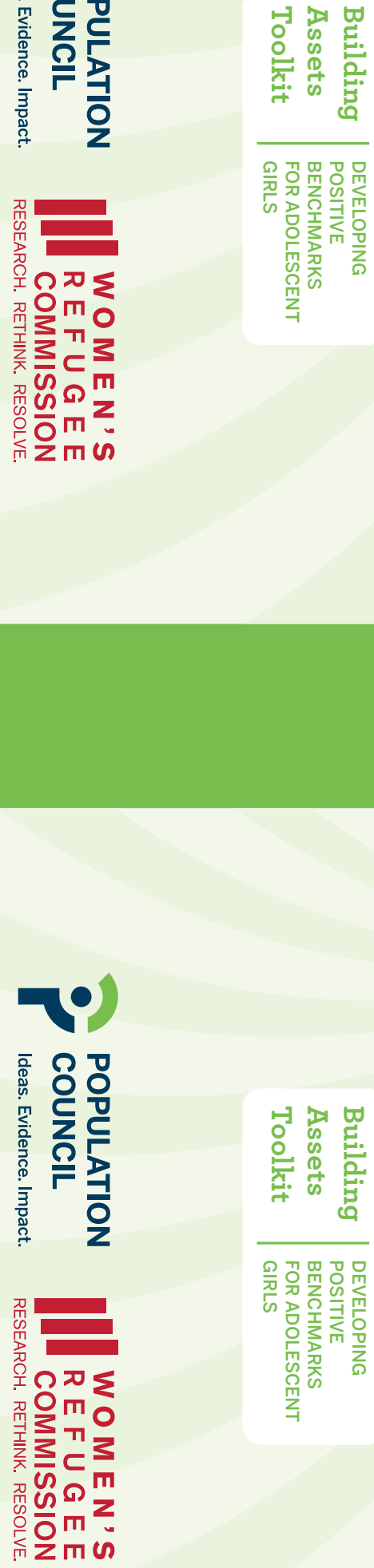
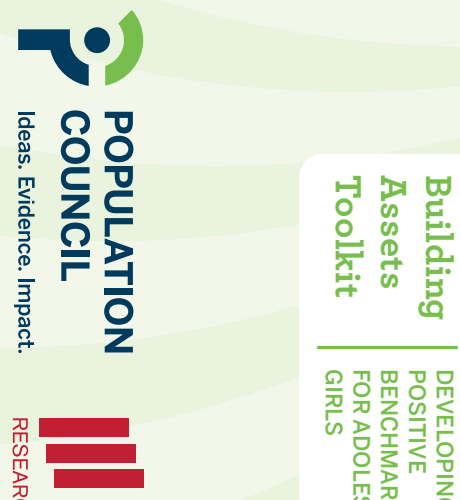

กิ工 $\cap$ ऽ

苗인

产 $\subset$

召心 $\boldsymbol{\omega}^{\mathrm{m}}$

을 而向心

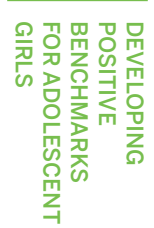

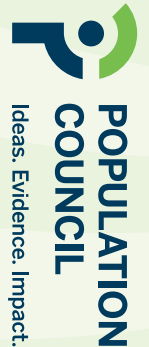

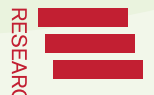

エฺ 备잉

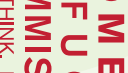
架 인

而两以 


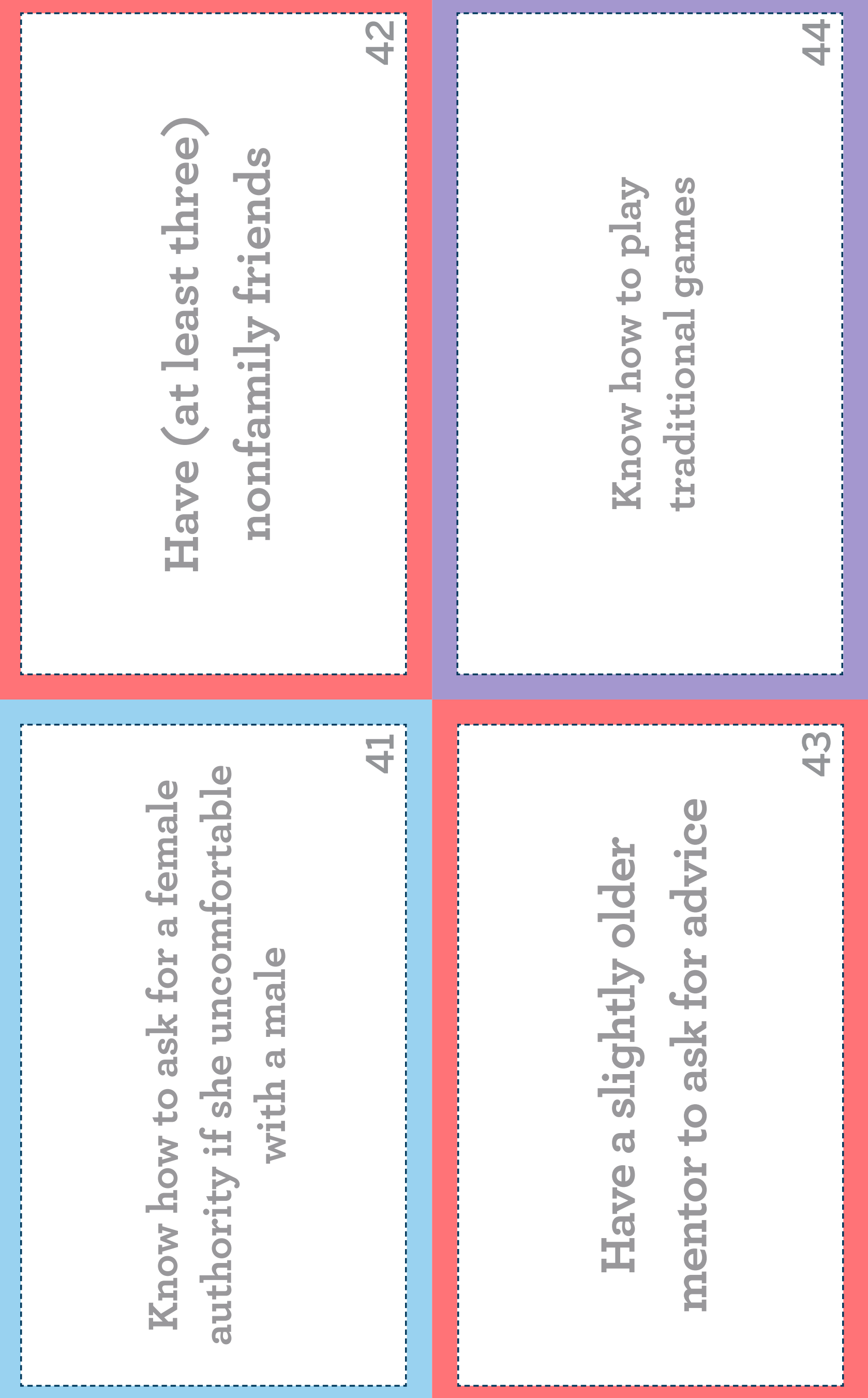



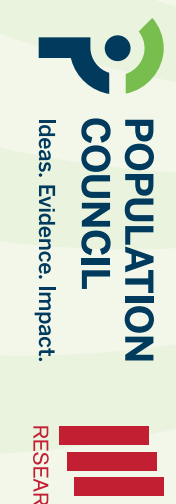
กิ1 $\Omega$ ס 꾼인 玄至飞 ○ $\mathrm{m}^{2}$

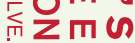
页
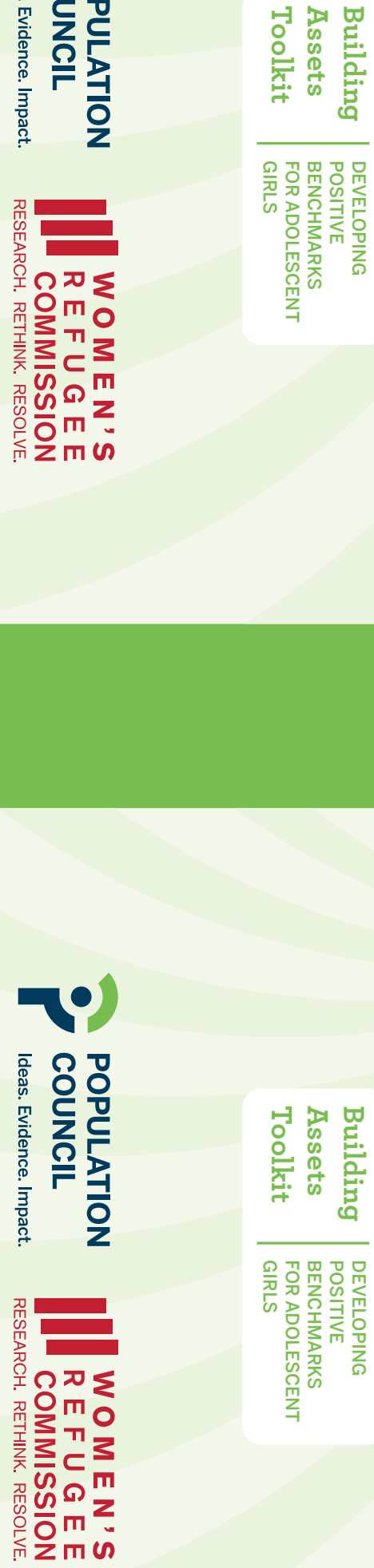
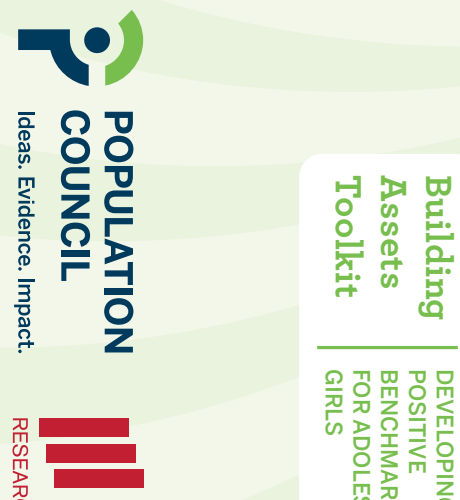

กิ工 $\cap$ ऽ

苗인

产 $\subset$

召心 $\boldsymbol{\omega}^{\mathrm{m}}$

을 而向心

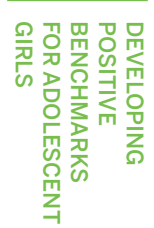

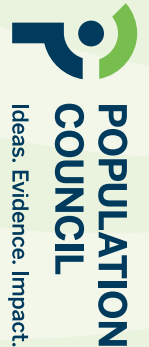

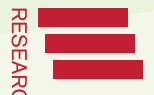

エฺ 备잉

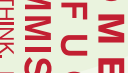
架 인

而两以 


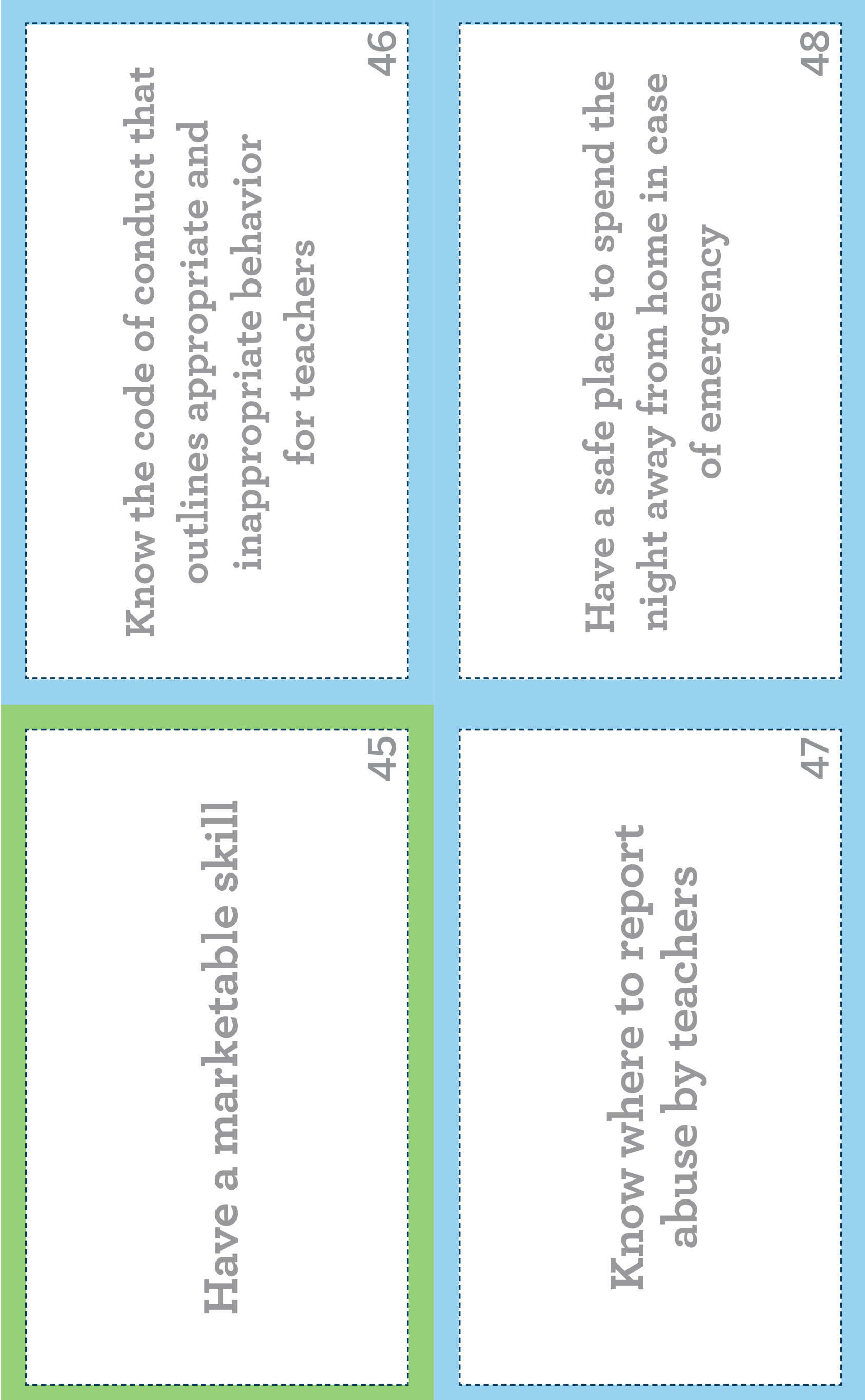



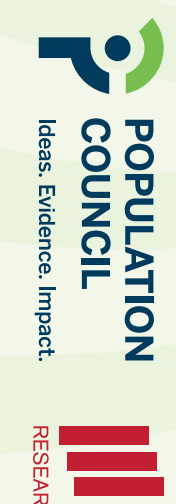
กิ1 $\Omega$ ס 꾼인 玄至飞 ○ $\mathrm{m}^{2}$

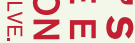
页
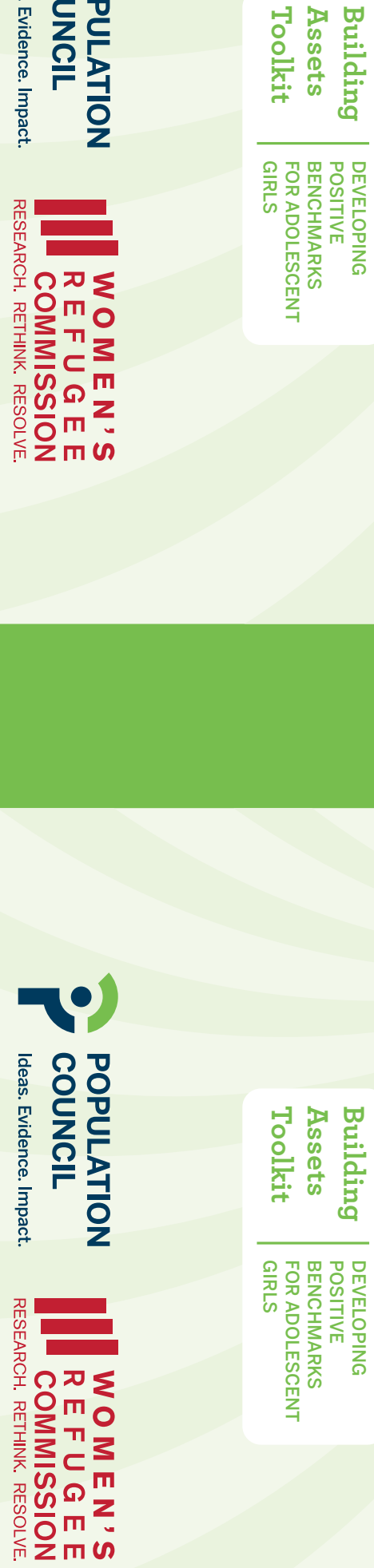
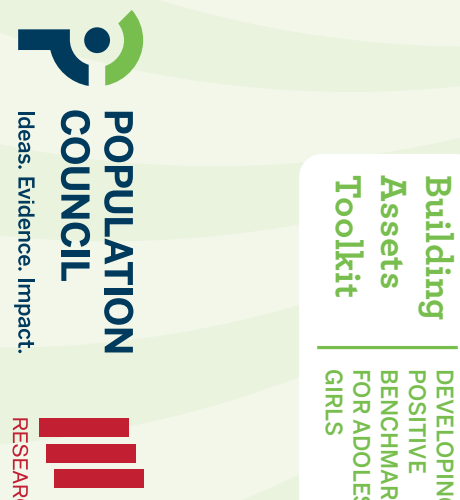

กิ工 $\cap$ ऽ

苗인

产 $\subset$

召心 $\boldsymbol{\omega}^{\mathrm{m}}$

을 而向心

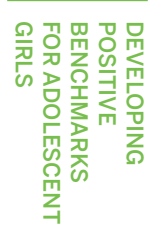

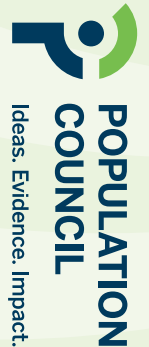

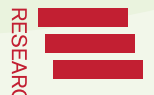

エฺ 备잉

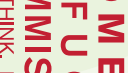
架 인

而两以 

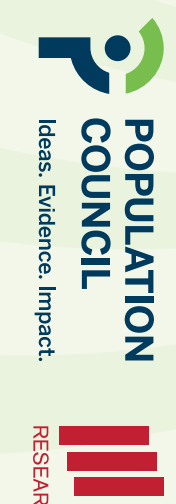
กิ1 $\Omega$ ס 꾼인 玄至飞 ○ $\mathrm{m}^{2}$

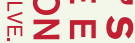
页
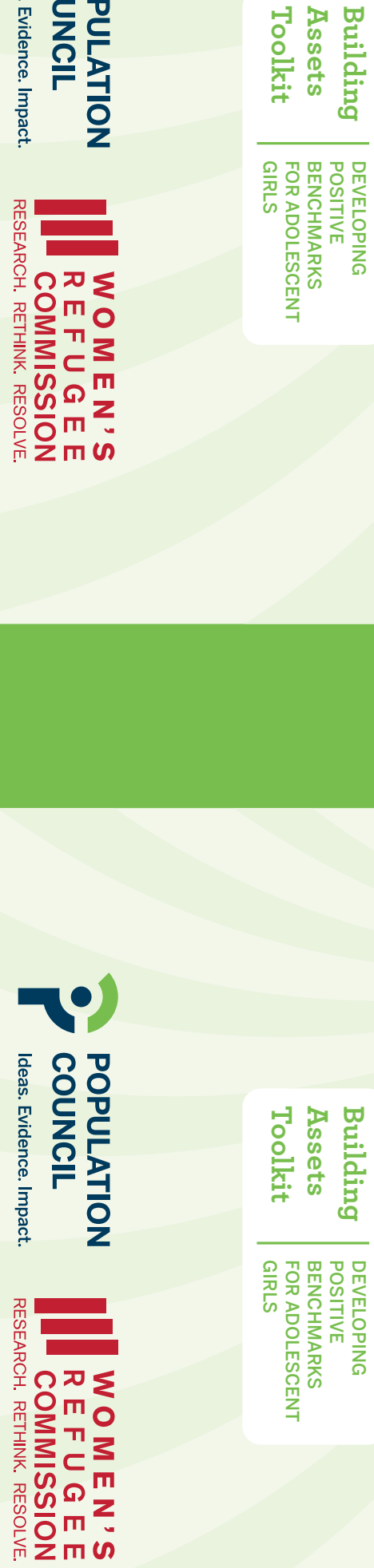
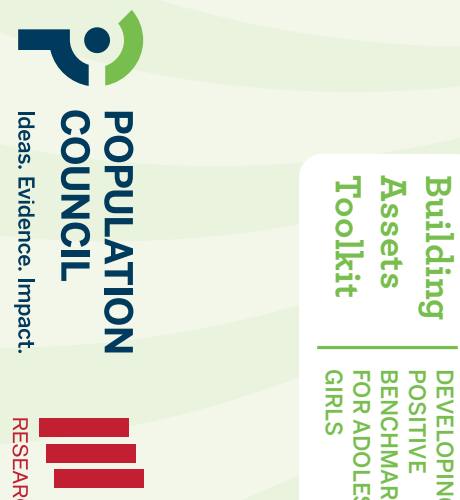

กิ工 $\cap$ ऽ

苗인

产 $\subset$

召心 $\boldsymbol{\omega}^{\mathrm{m}}$

을 而向心

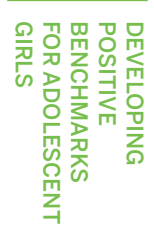

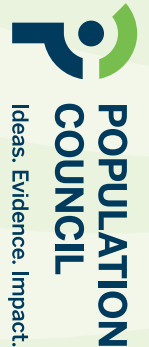

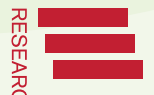

エฺ 备잉

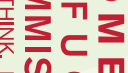
架 인

而两以 

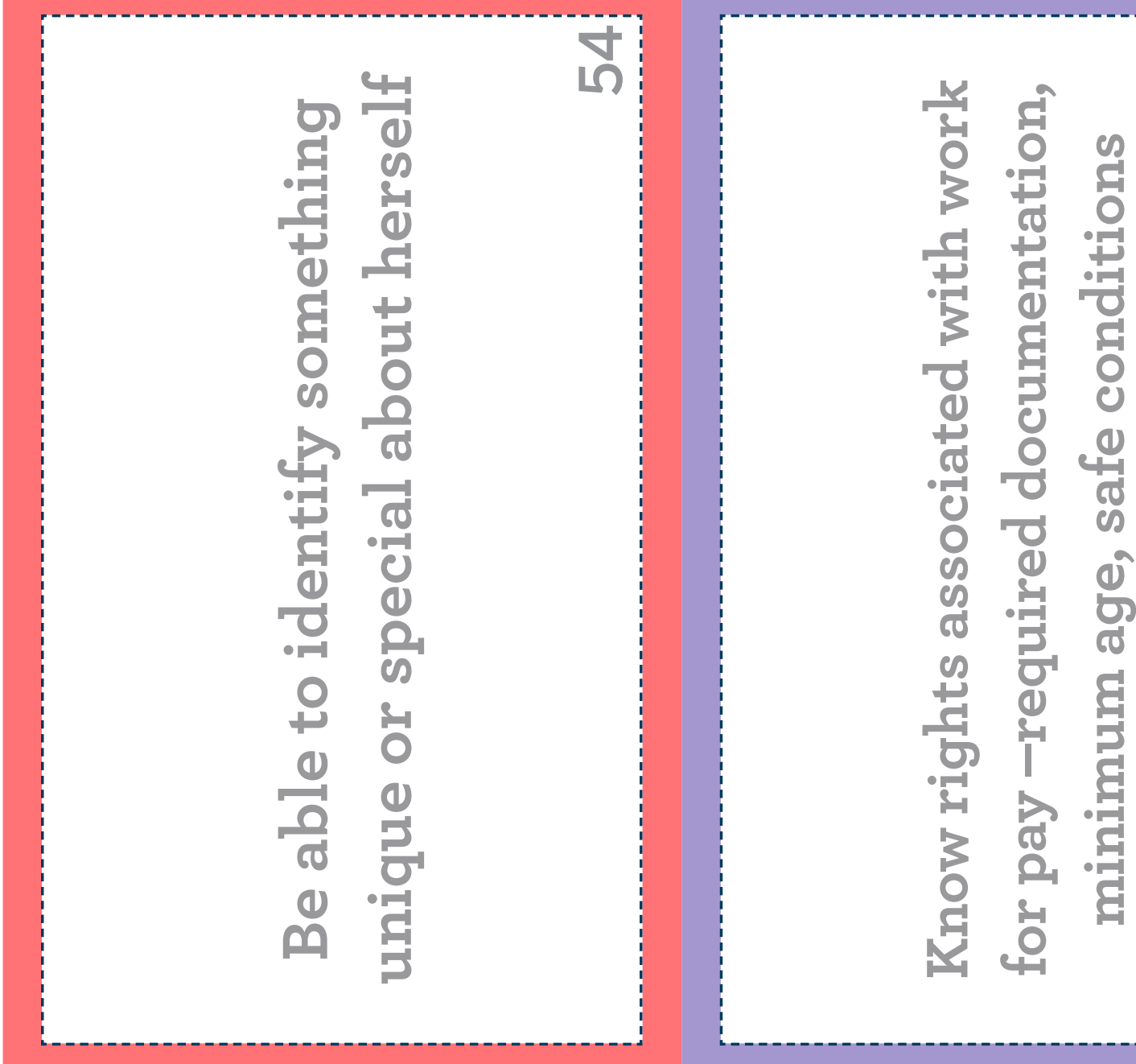

เ

ต

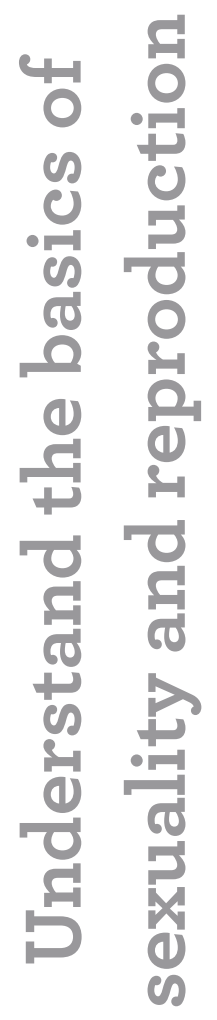

I

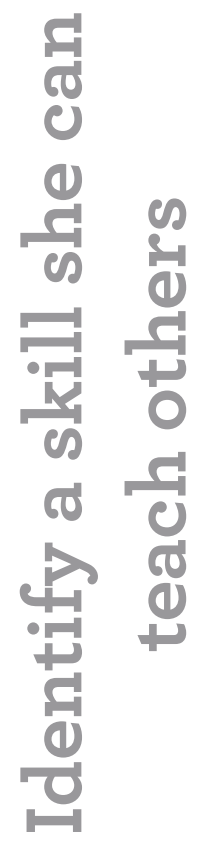



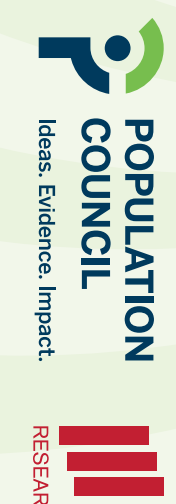
กิ1 $\Omega$ ס 꾼인 玄至飞 ○ $\mathrm{m}^{2}$

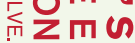
页
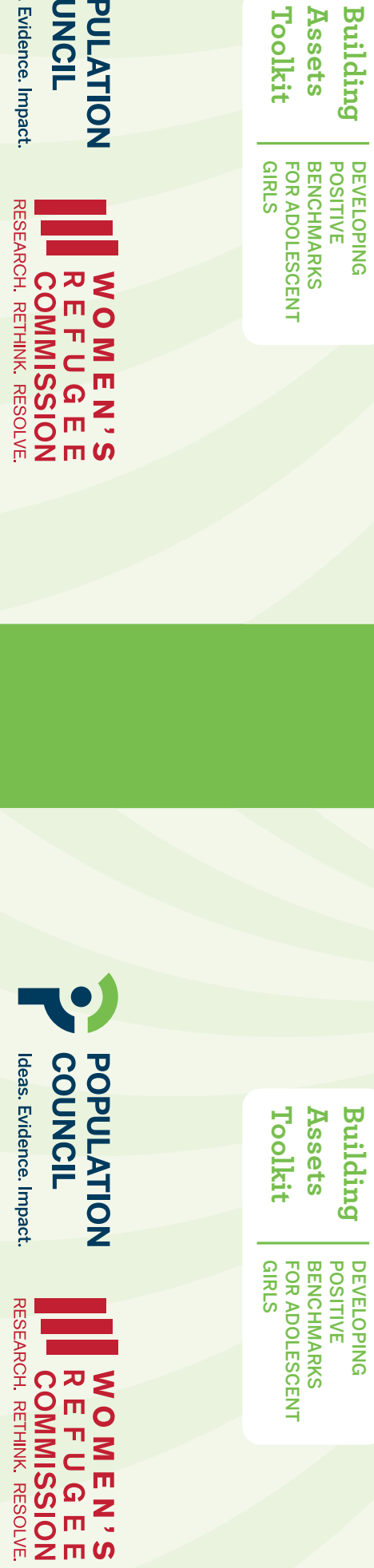
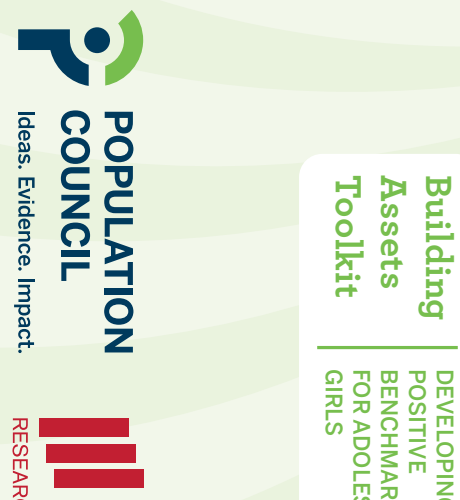

กิ工 $\cap$ ऽ

苗인

产 $\subset$

召心 $\boldsymbol{\omega}^{\mathrm{m}}$

을 而向心

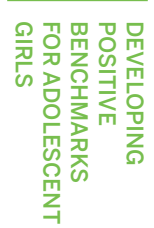

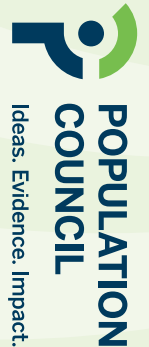

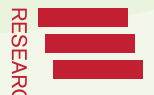

エฺ 备잉

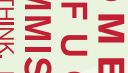
架 인

而两以 

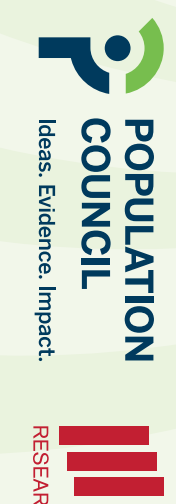
กิ1 $\Omega$ ס 꾼인 玄至飞 ○ $\mathrm{m}^{2}$

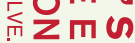
页
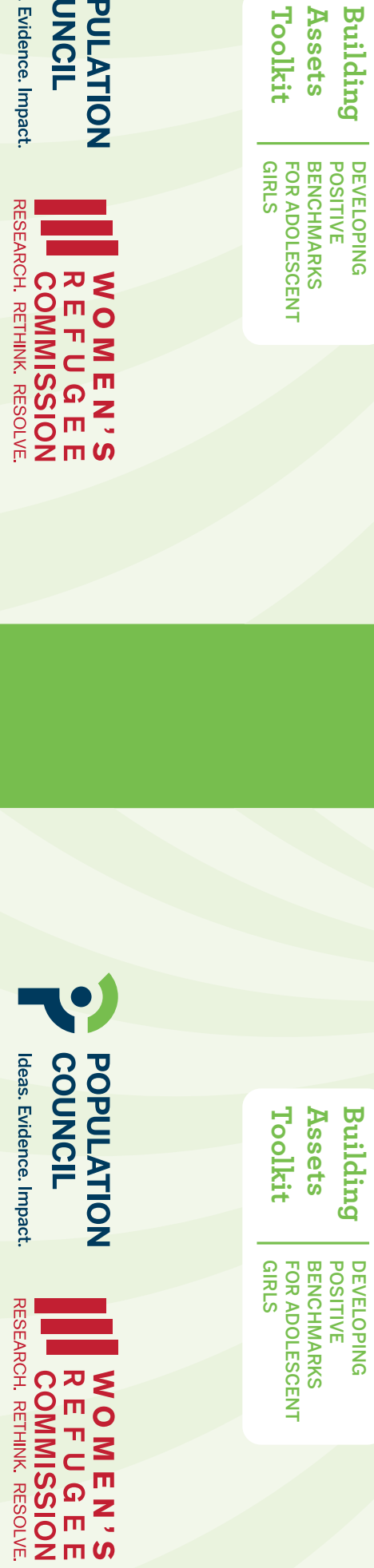
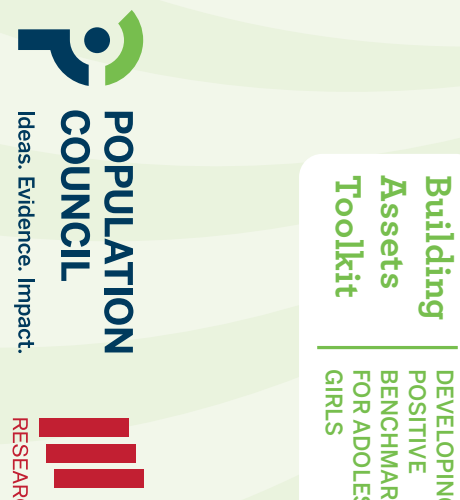

กิ工 $\cap$ ऽ

苗인

产 $\subset$

召心 $\boldsymbol{\omega}^{\mathrm{m}}$

을 而向心

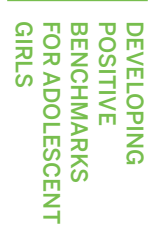

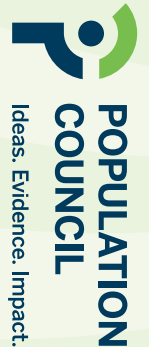

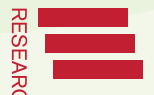

エฺ 备잉

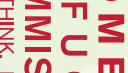
架 인

而两以 

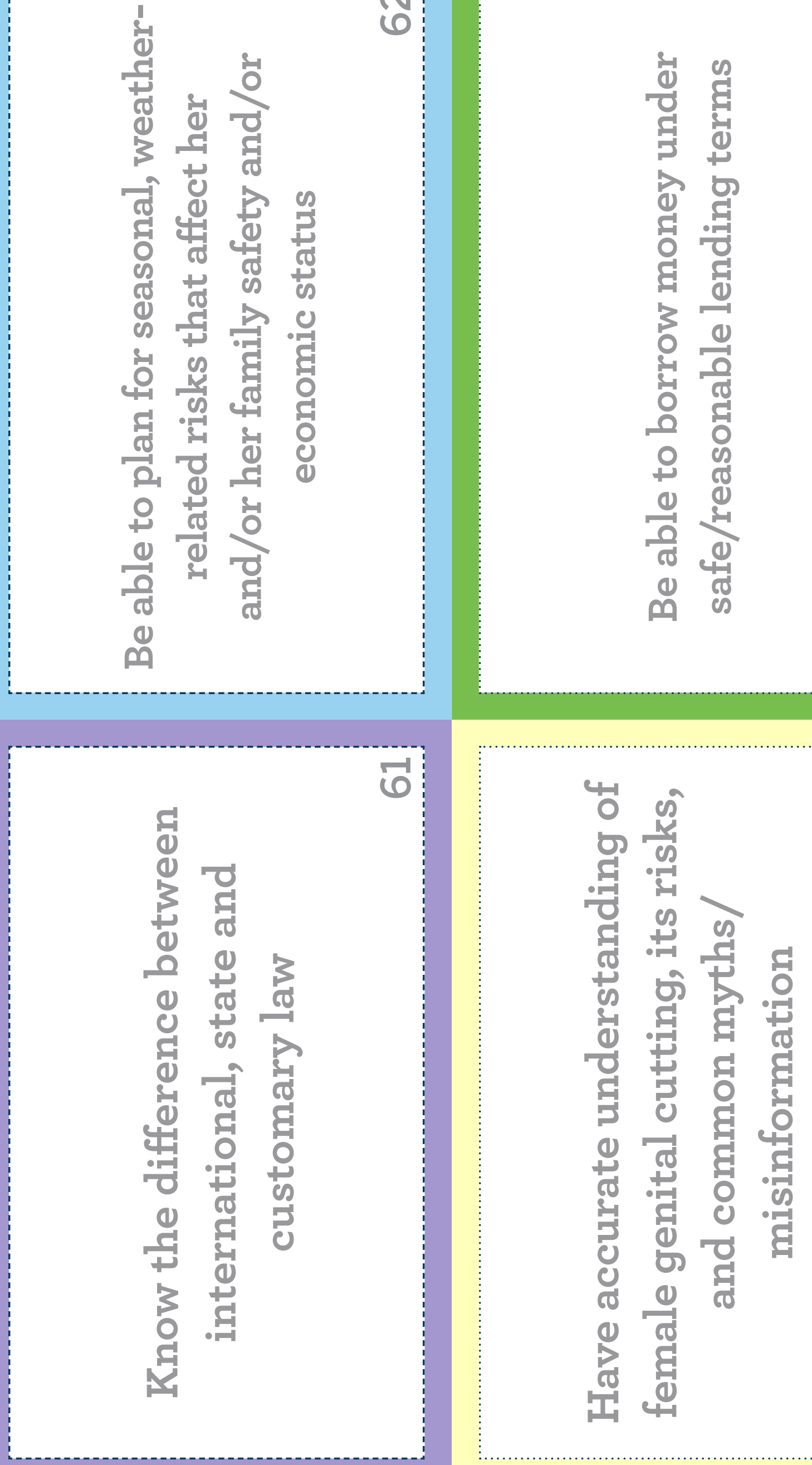

(0) 

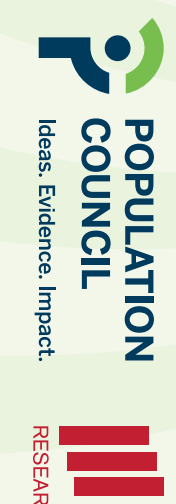
กิ1 $\Omega$ ס 꾼인 玄至飞 ○ $\mathrm{m}^{2}$

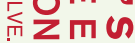
页
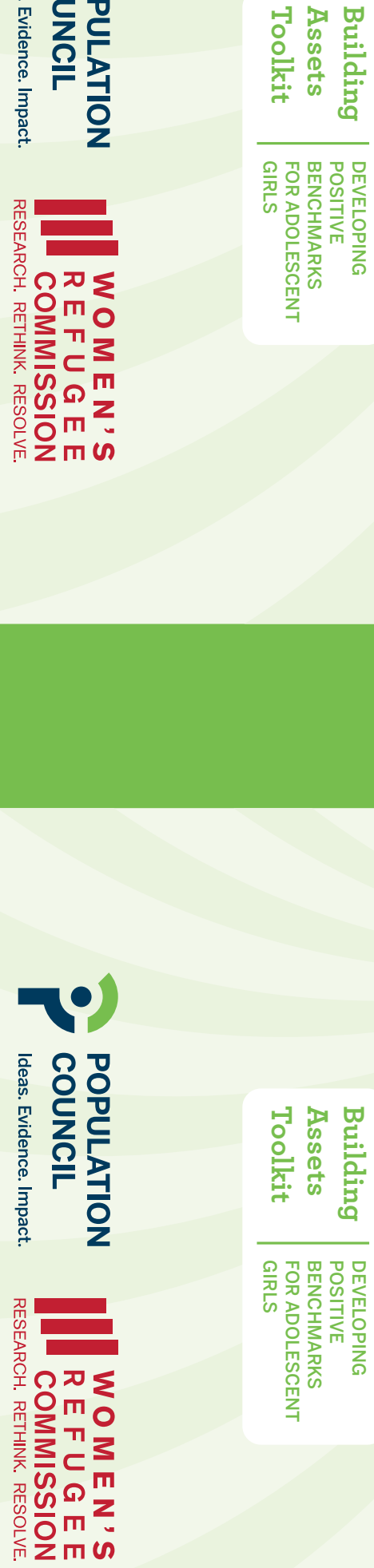
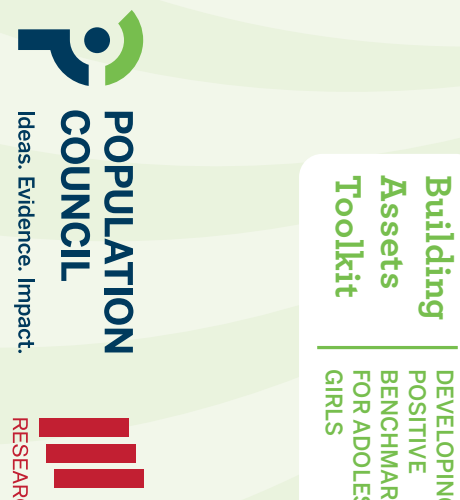

กิ工 $\cap$ ऽ

苗인

产 $\subset$

召心 $\boldsymbol{\omega}^{\mathrm{m}}$

을 而向心

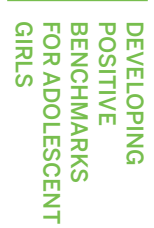

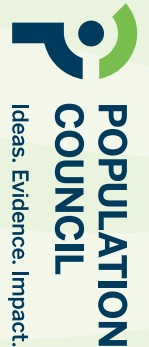

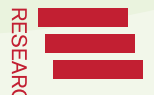

エฺ 备잉

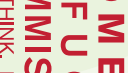
架 인

而两以 


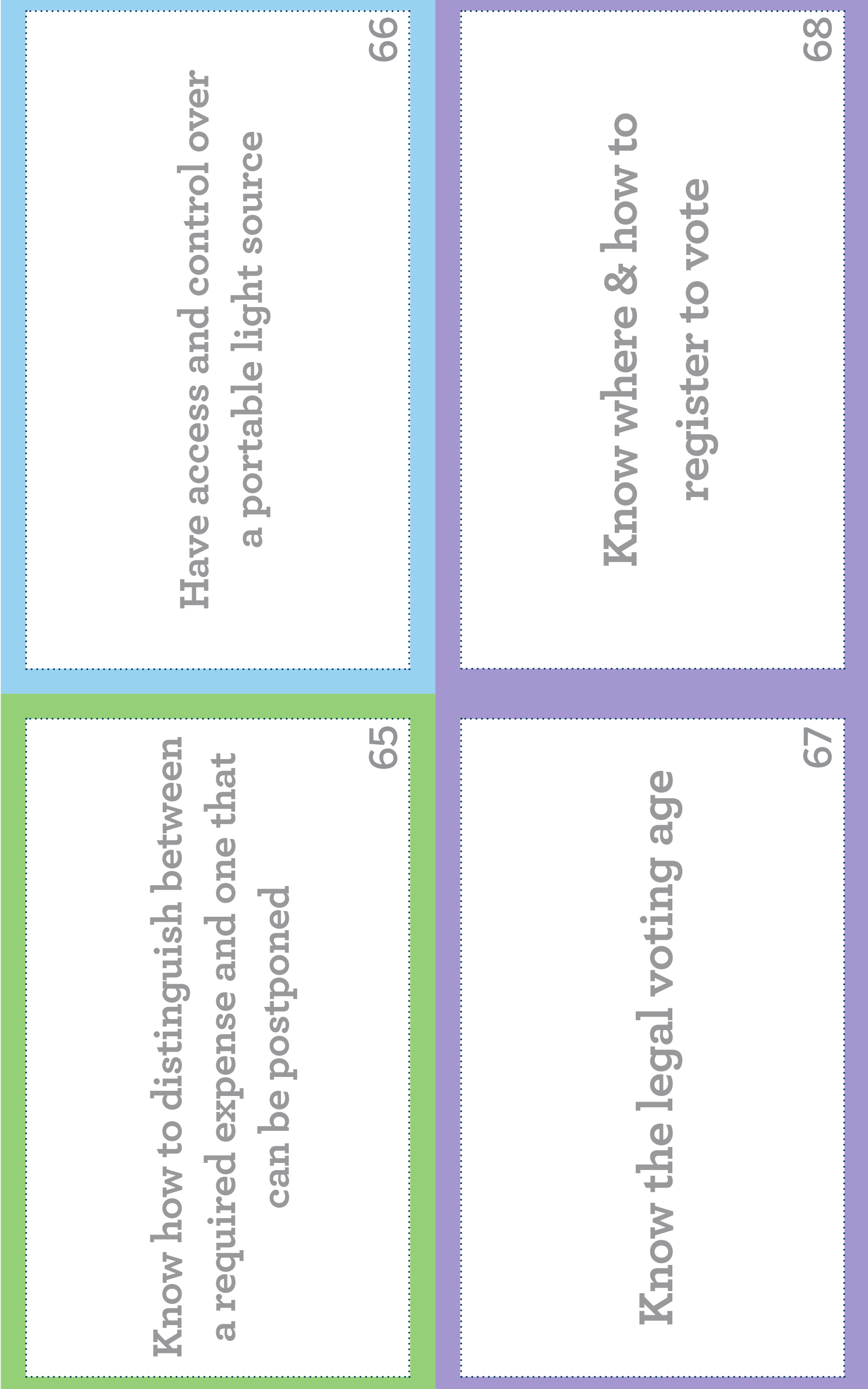



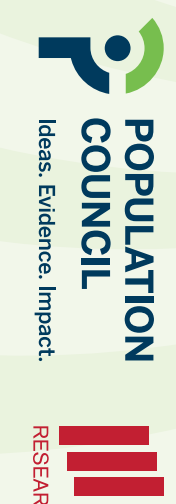
กิ1 $\Omega$ ס 꾼인 玄至飞 ○ $\mathrm{m}^{2}$

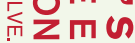
页
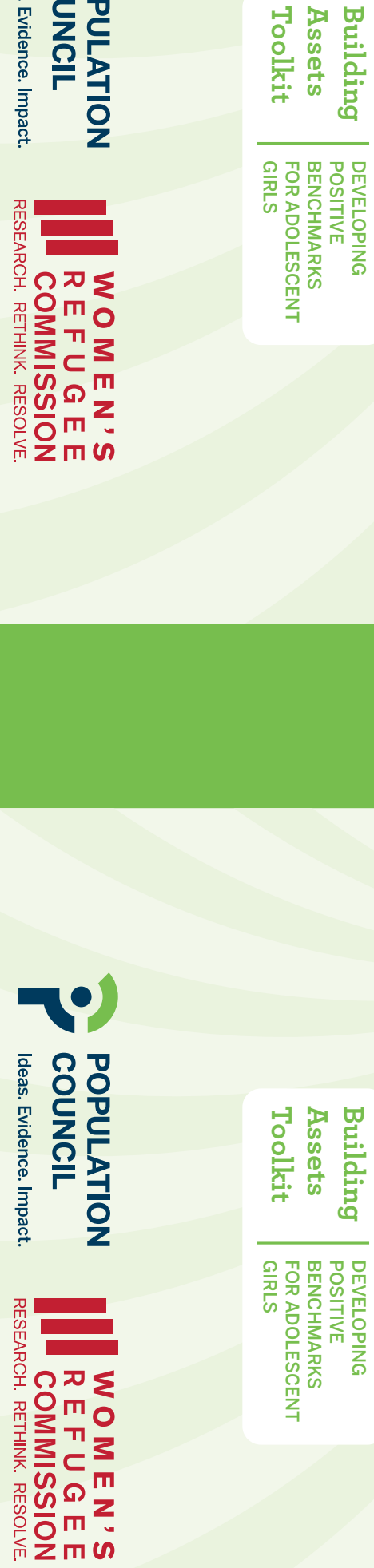
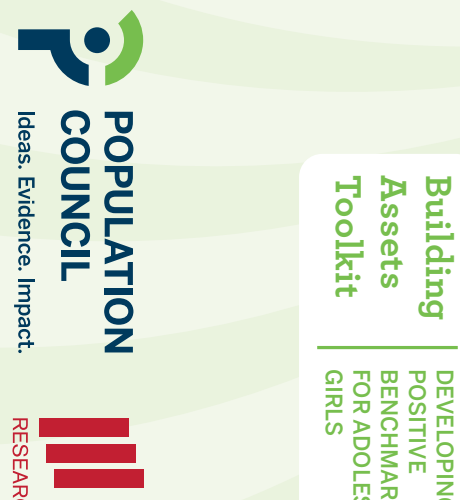

กิ工 $\cap$ ऽ

苗인

产 $\subset$

召心 $\boldsymbol{\omega}^{\mathrm{m}}$

을 而向心

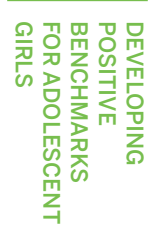

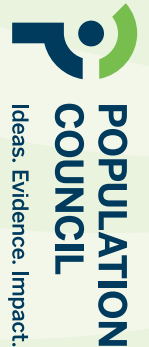

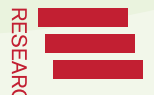

エฺ 备잉

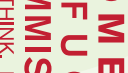
架 인

而两以 


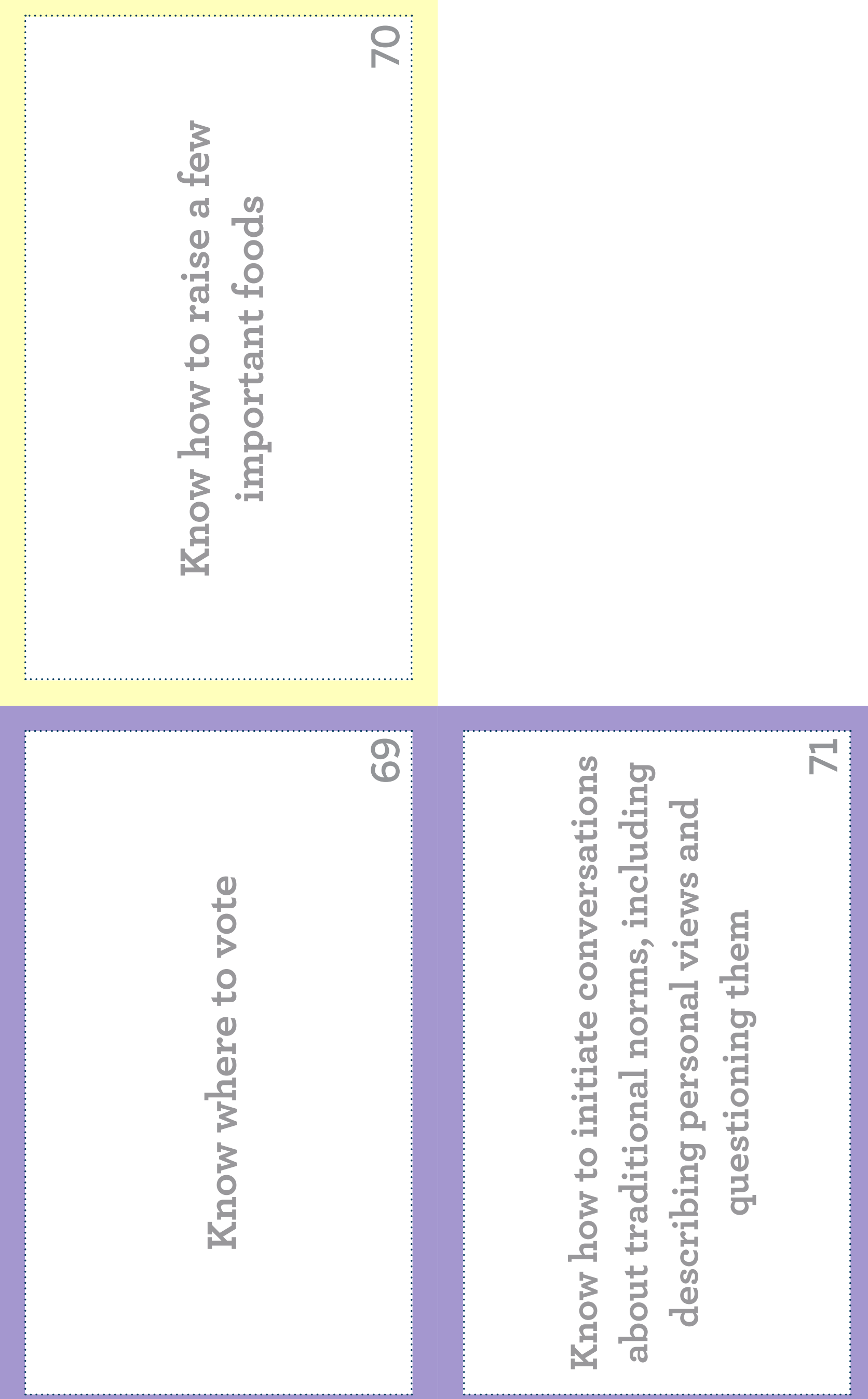



AGE CARDS 


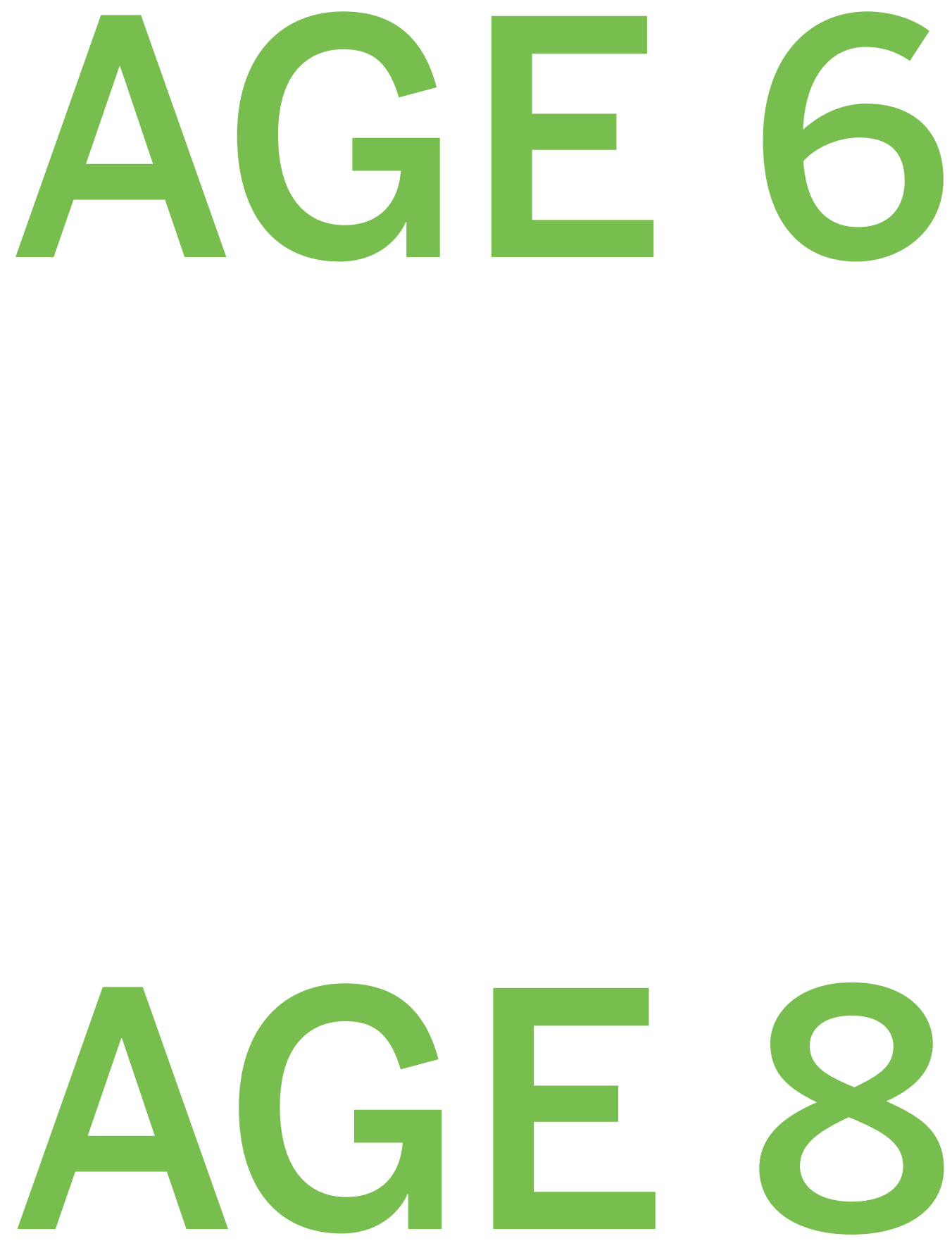


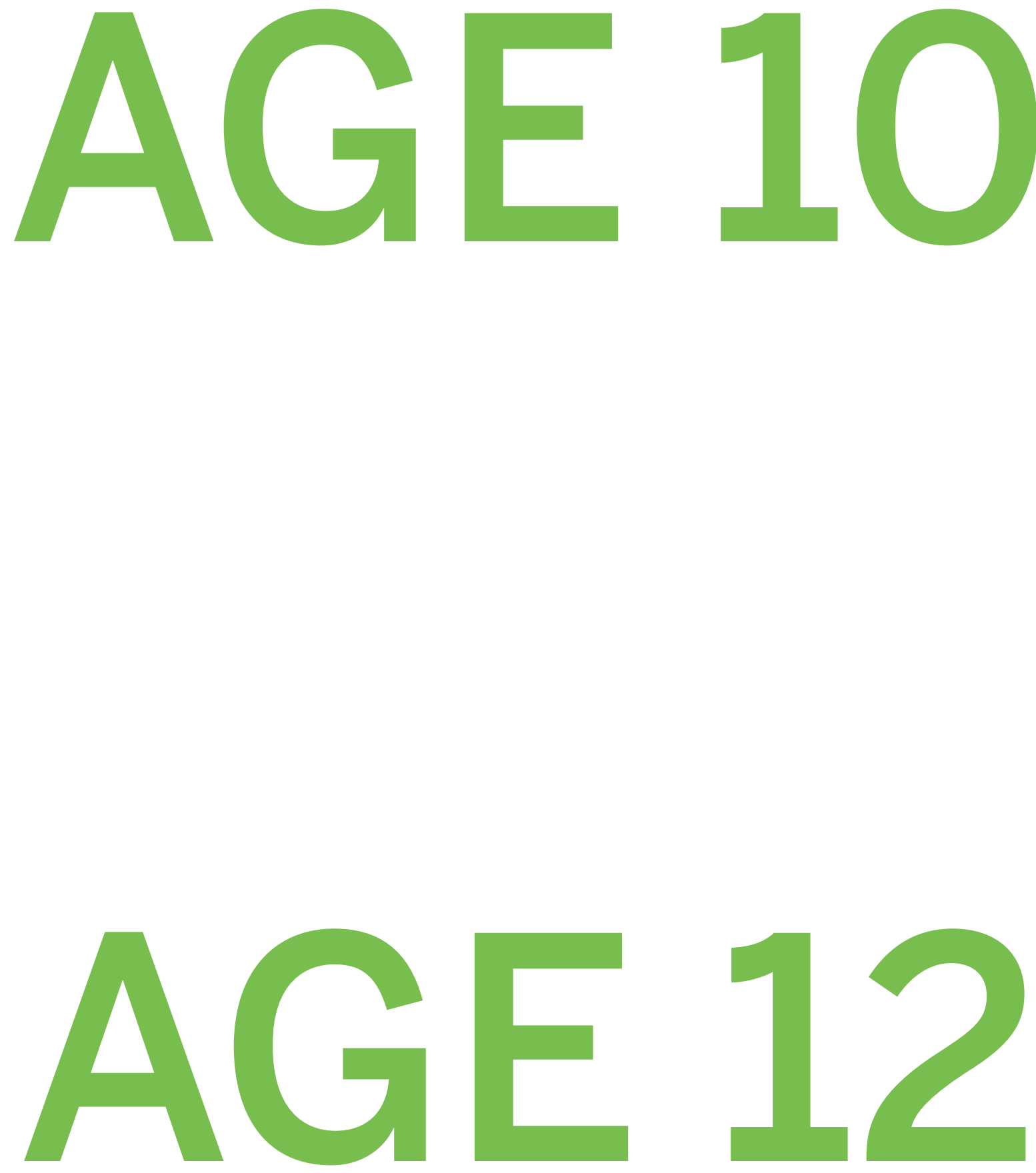


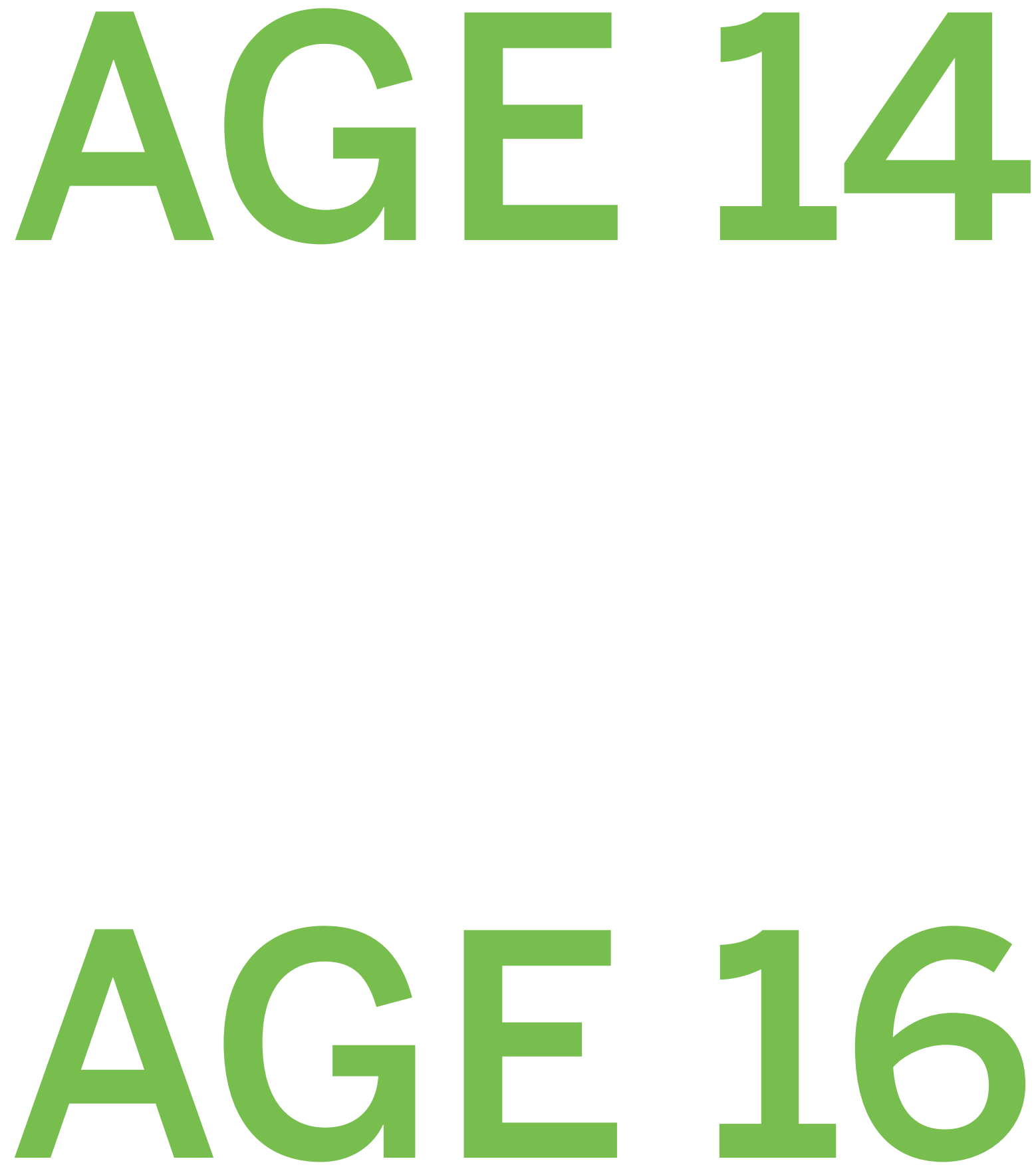


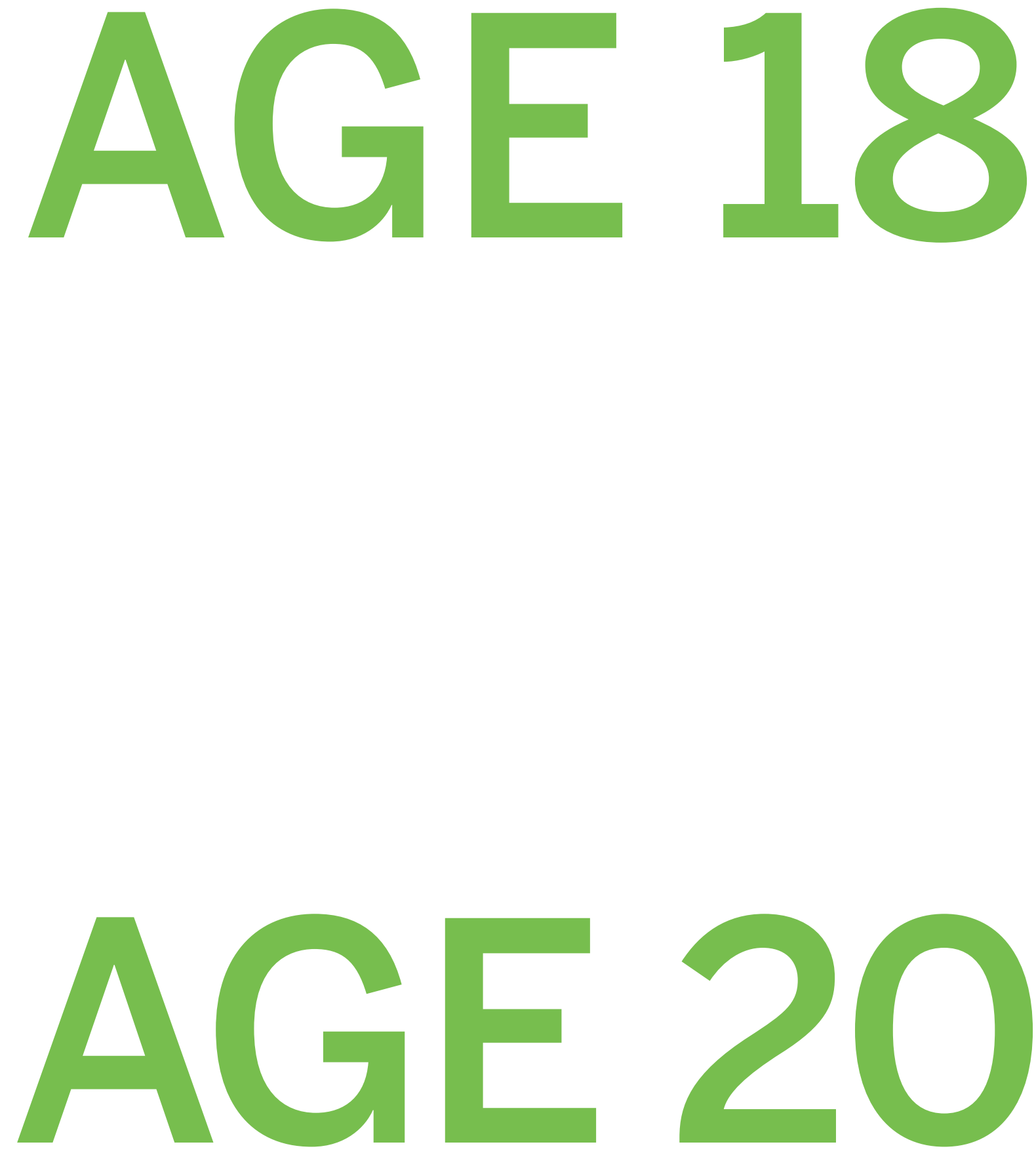